Geological Society of America

Field Guide 6

2005

\title{
Sheet-like emplacement of satellite laccoliths, sills, and bysmaliths of the Henry Mountains, Southern Utah
}

\author{
Sven Morgan \\ Department of Geology, Central Michigan University, Mt. Pleasant, Michigan 48858, USA \\ Eric Horsman \\ Basil Tikoff \\ Department of Geology and Geophysics, University of Wisconsin, Madison, Wisconsin 53706, USA \\ Michel de Saint-Blanquat \\ Guillaume Habert \\ LMTG-UMR5563/Observatoire Midi-Pyrénées, CNRS/Université Paul-Sabatier, 14 av. Edouard-Belin, 31400 Toulouse, France
}

\begin{abstract}
Small intrusions $\left(<3 \mathrm{~km}^{2}\right)$ on the margins of the Henry Mountains intrusive complex of southern Utah are exceptionally well exposed in three dimensions and have a variety of shapes. Our examination of the geometry, structures, and fabric of the Maiden Creek sill, Trachyte Mesa laccolith, and the Black Mesa bysmalith (cylindrical intrusion bounded by vertical faults) suggests that this range of intrusion geometry may reflect a continuum of igneous emplacement as volume increases through magma sheeting. Intrusions begin as thin sills and through incremental injection of additional sheets, inflate into laccoliths. Marginal wall rocks are strained and rotated upward. Further sheet emplacement leads to the formation of a fault at the margin of the inflating intrusion. This fault accommodates piston-like uplift of the intrusion's roof and results in the formation of a bysmalith.

All three of these intrusions exhibit evidence for sheeting, although the evidence is weakest on the margins of the Black Mesa bysmalith. Solid-state shear zones exist between sheets in the Maiden Creek sill and on the margins of the Trachyte Mesa laccolith. Cataclastic zones also separate sheets within the Trachyte Mesa laccolith. Evidence for sheeting in the interior of the Trachyte Mesa laccolith is solely based on differences in weathering and jointing patterns. Evidence for sheeting on the margins of the Black Mesa bysmalith is based on the differences in lineation patterns and also on the distribution of cataclastic zones.
\end{abstract}

Keywords: laccolith, Henry Mountains, sill, sheet, magma emplacement.

Morgan, S., Horsman, E., Tikoff, B., Saint-Blanquat, M.de, and Habert, G., 2005, Sheet-like emplacement of satellite laccoliths, sills, and bysmaliths of the Henry Mountains, southern Utah, in Pederson, J., and Dehler, C.M., eds., Interior Western United States: Geological Society of America Field Guide 6, p. xxx-xxx, doi: 10.1130/2005.fld006(14). For permission to copy, contact editing@geosociety.org. @ 2005 Geological Society of America 


\section{INTRODUCTION}

The intrusions of the Henry Mountains of south-central Utah provide an exceptional setting for the study of igneous emplacement processes. The igneous bodies intrude the welldocumented flat-lying stratigraphy of the Colorado Plateau and therefore displacement of the wall rocks resulting from emplacement of magma is well constrained (e.g., Gilbert, 1877; Hunt, 1953; Pollard and Johnson, 1973; Jackson and Pollard, 1988; Habert and de Saint Blanquat, 2004; Horsman et al., 2005). The intrusions are mid-Tertiary in age (Nelson et al., 1992) and therefore postdate the minor Laramide orogenic activity that affected this part of the Colorado Plateau. Consequently, fabric within the intrusions primarily reflects finite strain produced by magmatic flow during emplacement and lacks a significant concurrent or subsequent tectonic overprint.

The Henry Mountains are the type locality to examine laccoliths since G.K. Gilbert originated the term laccolite (1877) based on his pioneering work here in the late 1800s. Gilbert's mule- and horse-driven expeditions are themselves a significant accomplishment in physical endurance and scientific exploration, and well documented in Hunt's reprinting (1988) of Gilbert's field notes. Gilbert demonstrated that the igneous rocks of the Henry Mountains were actually intrusive (groundbreaking at the time) and he was one of the first to realize that magmas can deform their wall rocks. Gilbert envisioned a two-stage process of magma emplacement whereby the initial intrusion is sill-like, but with continued flow of magma, vertical growth is initiated and horizontal spreading ceases. The details of the growth of these intrusions have been debated ever since. It is the purpose of this trip to reexamine some of the same intrusions that Gilbert studied and to illustrate that at least in some intrusions, abundant evidence exists for the growth of the intrusion by the stacking of multiple magma sheets.

Hunt (1953), after years of detailed mapping in the Henry Mountains in the 1930s (also on horseback), reinterpreted the five main intrusive centers and/or mountains as stocks, not laccoliths. The principal difference being that a laccolith has a flat lying sedimentary "floor," and a stock continues downward with depth. Hunt (1953) agreed with Gilbert in that the smaller surrounding intrusions were laccoliths and were fed from the large intrusive centers. Detailed mapping and geophysical work by Jackson and Pollard (1988) led to an interpretation more in agreement with Gilbert (1877); i.e., the five main intrusive centers were "floored" laccoliths and not stocks.

This field guide concentrates on the small $(<3 \mathrm{~km}$ diameter) intrusive bodies that occur on the east side of the Mount Hillers intrusive center: the Maiden Creek sill, Trachyte Mesa laccolith, and the Black Mesa bysmalith. We will also briefly examine the Sawtooth Ridge intrusion. We call these small intrusions satellites, because they are located between 5 and $10 \mathrm{~km}$ from the closest intrusive center (Mount Hillers), their magma volumes are small relative to the main intrusive centers, and they are radially distributed about the intrusive centers. The elongate shape of
Trachyte Mesa is also oriented along a line that intersects Mount Hillers, and magmatic lineations within the Trachyte Mesa laccolith are also subparallel to this line. These satellite intrusions, on a much smaller scale, resemble the intrusive centers in composition, shape, and style of emplacement (contact geometries are similar). In contrast to their larger neighbors, the satellites are much better exposed and more readily accessible (low elevation and proximity to roads). All are close to Utah Highway 276 and to dirt roads, which allows visitation of all these intrusions in one or two days.

Our work is different than previous studies in that we have focused on the fabrics within the intrusions, as well as the structures and geometry of the intrusions. In particular, we have focused on the role of discrete magma pulses, observed in the field as magma sheets, in constructing these igneous bodies. We hypothesize that these three intrusions - the Maiden Creek sill, Trachyte Mesa laccolith, and the Black Mesa bysmalith (from smallest to largest) - may reflect the evolution of a magma chamber with increasing magma input. Alternatively stated, the Black Mesa bysmalith may have originated as a sill (a Maiden Creek "phase") that became a laccolith (a Trachyte Mesa "phase") before evolving into its present bysmalith form (a bysmalith is a cylindrical intrusion with vertical faults as contacts, whereas a laccolith is more dome-like). We can show many rock exposures that illustrate the multiple sheet-like construction of the Maiden Creek Sill and Trachyte Mesa laccolith. We also have evidence, although weaker, for slightly more cryptic sheets within the upper portion of the Black Mesa bysmalith.

\section{GEOLOGY AND HISTORY OF THE HENRY MOUNTAINS}

The Henry Mountains of south-central Utah are a 90-kmlong and 30-km-wide Tertiary igneous complex on the Colorado Plateau (Fig. 1). Although they are the largest of seven laccolithic ranges found on the Colorado Plateau (Stokes, 1988), they were one of the last surveyed and the last-named ranges in the lower 48 states. John Wesley Powell called them the Unknown Mountains on his first trip down the Colorado River in 1869 (Kelsey, 1990). Powell named them in 1871-1872 after Joseph Henry, a close friend and secretary of the Smithsonian Institution, on his return voyage down the Colorado River. The first non-native set foot in the Henrys in 1872, when A.H. Thompson, a geographer from Powell's second party, explored the northern peaks; Mount Ellen is named after Thompson's wife (Fillmore, 2000). In 1875 Powell assigned Grove Karl Gilbert to study the "volcanic" mountain range, and Gilbert made two trips (two weeks in 1875 and two months in 1876) (Fillmore, 2000).

The range is composed of five distinct igneous centers that were emplaced into basically flat-lying stratigraphy (regional dips of $1-2^{\circ} \mathrm{W}$ ). Ten kilometers to the west, the stratigraphy is abruptly upturned in the Waterpocket Monocline, and the canyons of the Colorado River are $<10 \mathrm{~km}$ to the southwest. The peaks attain heights of over 11,000 ft, while the elevation of the 
surrounding flat-lying rocks of the plateau hovers around 4000 $5000 \mathrm{ft}$. A striking aspect to the Henry Mountains, besides their size and nature of origin, is the abruptness with which the mostly Mesozoic wall and roof rocks rotate upward on the flanks of the intrusions to produce these mountains; this is readily observed from Hwy 95 and Hwy 276, which parallel the mountain chain. Even though the mapped intrusives have steep margins, it is evident based on the much more subtle slopes of the immediately surrounding sedimentary layers that these intrusions expand over a much greater area than what is actually exposed.

Mount Hillers is the best exposed of the five Henry Mountains intrusive centers and presently forms a dome with a diameter of $\sim 15 \mathrm{~km}$. Several steep, narrow canyons cut into Mount Hillers and expose cross sections through numerous intrusions radiating away from the center of the dome. The sedimentary rocks on the top have also been eroded away partially exposing the igneous core. Assuming that there were sedimentary rocks on top of Mount Hillers, the vertical displacement of the sedimentary rocks is $\sim 2.5 \mathrm{~km}$ (Hunt, 1953; Jackson and Pollard, 1988).

The sedimentary section is dominated by sandstones and shales that range in age from Permian to Cretaceous and is $\sim 2.7 \mathrm{~km}$ thick (Peterson et al., 1980; Jackson and Pollard, 1988). Jackson and Pollard (1988) determined that at the time of intrusion, the intrusives in the Henry Mountains were buried by 3-4 km of sedimentary overburden.

\section{FIELD TRIP}

\section{Overview of Day 1}

In the morning we will examine the Maiden Creek sill, and in the afternoon we will begin to examine the Trachyte Mesa laccolith. Note: This road log begins in Hanksville, Utah. Mile markers on Hwy 95 start at 0 at the intersection with Hwy 24 in Hanksville.

\section{Directions to Stop 1.1}

Go east (and south) on Utah Hwy 95.

Mile marker 2 (while driving by). At two o'clock (treating the car, in map view, as a clock, the front of the car is twelve o'clock, passenger side is three o'clock, etc.) is the Mount Ellen intrusive center. This is one of the five main intrusive centers in the Henry Mountains. There are two prominent mountains located at the periphery of Mount Ellen. Table Mountain is a mesa on the north end of the intrusive complex, and Bull Mountain is a more cylindrical looking mountain on the east side of the intrusive complex. Both mountains are bysmalith intrusions similar to Black Mesa, which we will observe later.

Mile marker 13 (while driving by). Shallowly dipping striped sediments E of here are the Carmel, Summerville, and Morrison Formations. The desert floor we are driving on is the Entrada Sandstone.

Mile markers 17-18 (while driving by). Reddish, eolian sediments of the Entrada Formation in a small canyon.

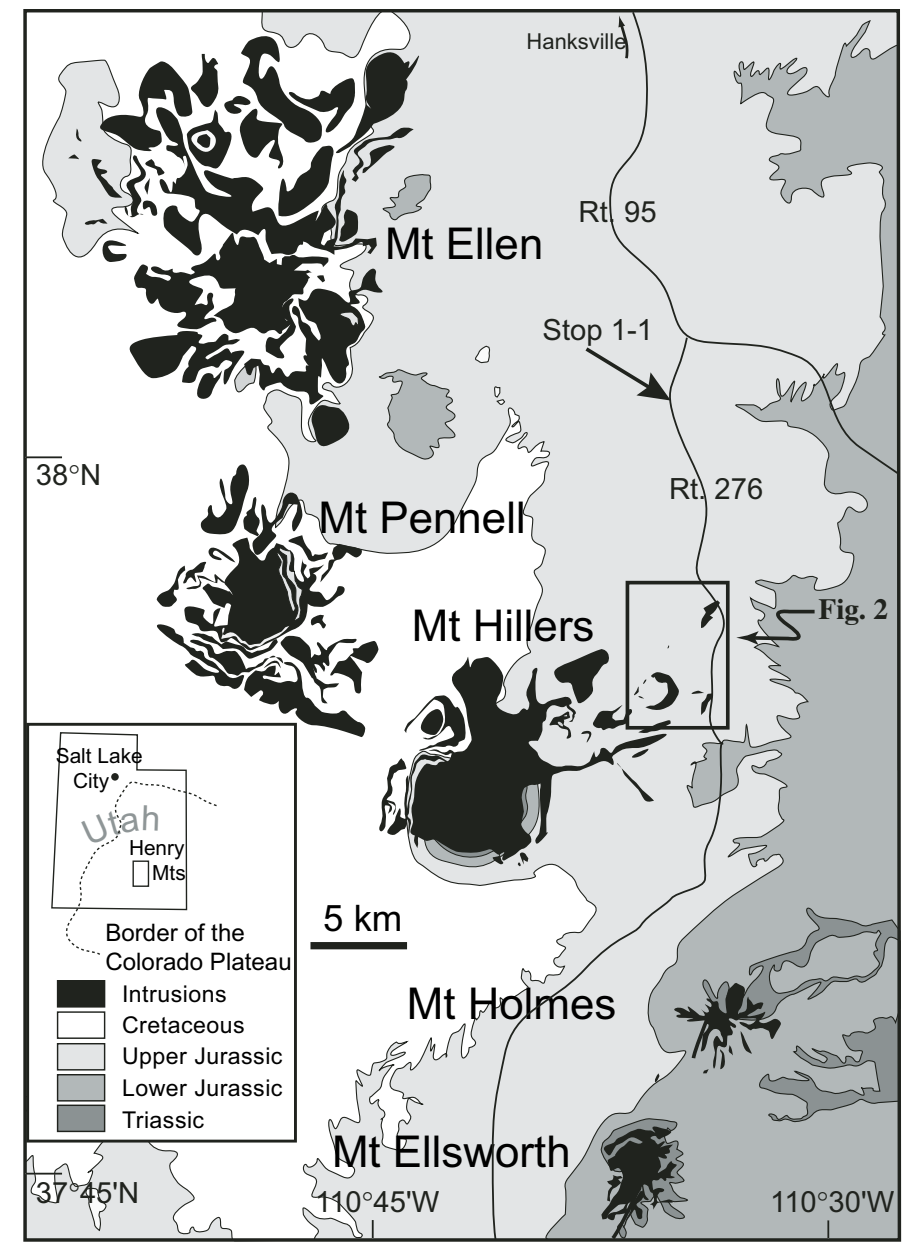

Figure 1. Regional map showing the area of study (small rectangle), Stop 1.1, and the five intrusive centers and peaks of the Henry Mountains, Utah.

Mile marker 26. Reset odometer to zero. Turn right onto Utah Hwy 276 toward Ticaboo. Mile markers start at 0 at the intersection with Utah Hwy 95. Drive $1.7 \mathrm{mi}$ to a small rise in the road and pull over on the side of the road for Stop 1.1.

\section{Stop 1.1: Overview of Henry Mountain Intrusive Centers}

The five intrusive centers of the Henry Mountains are visible from this point (Fig. 1). Looking due south along the road (and calling this 12 o'clock), Mount Holmes is at 12, Mount Ellsworth at 12:30, Mount Hillers at 1, Mount Pennell at 3, and Mount Ellen at 5. Each of these intrusive centers is composed of many component igneous intrusions. Mounts Ellsworth and Holmes are the smallest intrusive centers, and the exposed igneous rocks are composed of dikes and sills and a few relatively small laccoliths. Sedimentary rocks dominate the margins and can be traced almost to the top. The sedimentary layering is steeply inclined, indicating that more igneous rocks are beneath. Mount Ellen is the largest of the three northerly mountains and all three 
are composed of a great many intrusions with a wide range of sizes and geometries. The sedimentary layering is best exposed at the base of these intrusions and intermittently exposed through the middle elevations at various dips.

On the east flank of Mount Hillers, the Black Mesa and Sawtooth Ridge intrusions are visible on the skyline (Fig. 2). A sheer cliff forms the east side of the Black Mesa bysmalith and Sawtooth Ridge is noted by its prominent jagged edge against the skyline. Directly in front of us (middle ground), the Trachyte Mesa intrusion is exposed. The Maiden Creek sill is exposed just east of Black Mesa. Our strategy is to visit the least-developed intrusions first (i.e., the earliest stages in a possible continuum of development of an inflating magma chamber and/or intrusion), and visit the more-developed intrusions later. From here we visit the Maiden Creek sill for Stops 1.2-1.8, break for lunch, and then spend the afternoon at the Trachyte Mesa laccolith for Stops 1.9-1.13.

\section{Directions to Stop 1.2}

Continue south on Rt. 276. At mile 6.7, turn right onto dirt road. This is immediately $(<100 \mathrm{~m})$ before mile marker 7 on

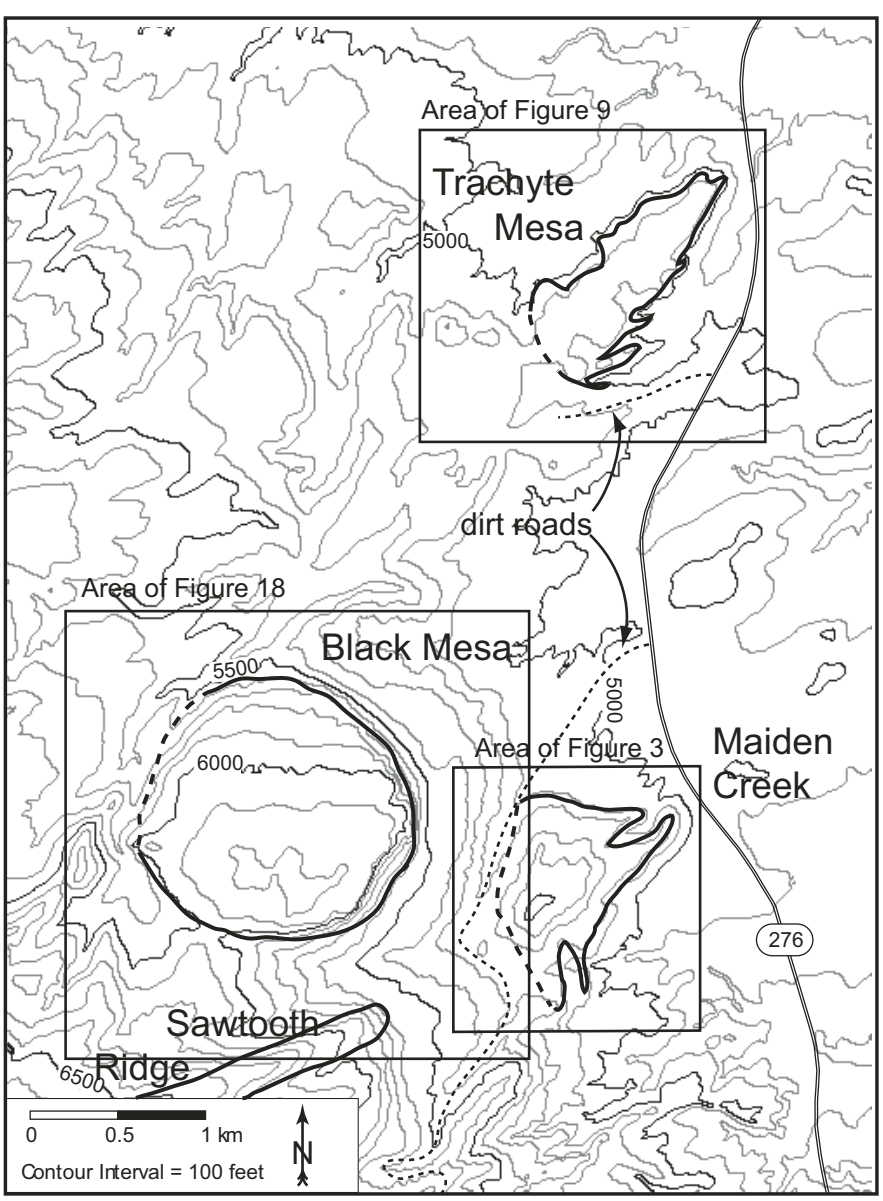

Figure 2. Topographic map of the area NE of Mount Hillers showing the satellite intrusions to be studied on this trip.
Utah Hwy 276. At mile 9.7, park on side of dirt road where road turns SE and there is some room to park in the bend. Walk ESE down the stream valley for $\sim 0.5 \mathrm{~km}$ (Fig. 3 ) until igneous rocks are seen in the stream bottom.

\section{Part I: The Maiden Creek Sill}

\section{Stop 1.2: Composition and Top Contact of the Maiden Creek Sill}

GPS (UTM): 536090, 4195836, zone 12, NAD27. Main points: (1) Composition and texture of the Maiden Creek sill. (2) The geometry of the body is a thick $(\sim 25 \mathrm{~m})$ sill. (3) The top contact contains solid-state fabric in the uppermost $\sim 3 \mathrm{~cm}$, the remainder of the intrusion contains magmatic fabrics. Lineation and foliation are generally parallel in both fabric types.

This stop provides a good spot to view the basic cross-sectional geometry of the Maiden Creek sill (Figs. 4 and 5). The planar-horizontal top contact of the intrusion with the overlying Entrada Sandstone is well exposed here. We will soon examine the planar-horizontal bottom contact of the intrusion in the steepwalled gorge $\sim 150 \mathrm{~m}$ east of here. The intrusion is generally $\sim 25 \mathrm{~m}$ thick but thins toward its margins in some areas. The horizontal, concordant top and bottom contacts of the intrusion lead us to call this a sill. However, the map view geometry of the intrusion is considerably more complex, as will become apparent shortly.

This stop also provides an introduction to the igneous rock of the Henry Mountains, which is a mostly homogeneous plagioclase-hornblende porphyry in which phenocrysts of feldspar and amphibole lie in a very fine-grained gray matrix (Fig. 6; see also Hunt, 1953; Engel, 1959; Nelson et al., 1992). In the Maiden Creek sill, feldspar phenocrysts make up 30\%-35\% of the rock by volume and are generally euhedral laths $0.2-1 \mathrm{~cm}$ in diameter. Amphibole phenocrysts make up 5\%-15\% of the rock by volume and are euhedral needles $0.1-0.5 \mathrm{~cm}$ in length. Other phenocrysts include euhedral to subhedral oxide grains, which generally have a maximum diameter of $0.2 \mathrm{~mm}$ and make up $<2 \%$ of the porphyry by volume, and apatite and sphene, both of which are generally euhedral and $<1 \%$ by volume. The very fine-grained matrix generally makes up $50 \%$ or more of the rock and is composed of microcrystalline feldspar, amphibole, and oxides.

Because of the well-exposed upper contact of the intrusion at this location, we can examine the relationship between the contact and fabric development in the igneous rock. The outermost $\sim 3 \mathrm{~cm}$ of the intrusion generally have well developed solidstate fabric, which is defined here by the cataclastic stretching of feldspar and amphibole phenocrysts (Fig. 6C). These deformed phenocrysts define a prominent lineation. More than $\sim 3 \mathrm{~cm}$ from the contact, solid-state fabric is essentially nonexistent and magmatic fabric is developed instead. This magmatic fabric is defined by the preferential alignment of undeformed phenocrysts, particularly elongate amphibole crystals (Fig. 6B). In locations where both solid-state and magmatic fabrics are exposed, foliation and lineation orientations in both fabric types of fabric are generally 


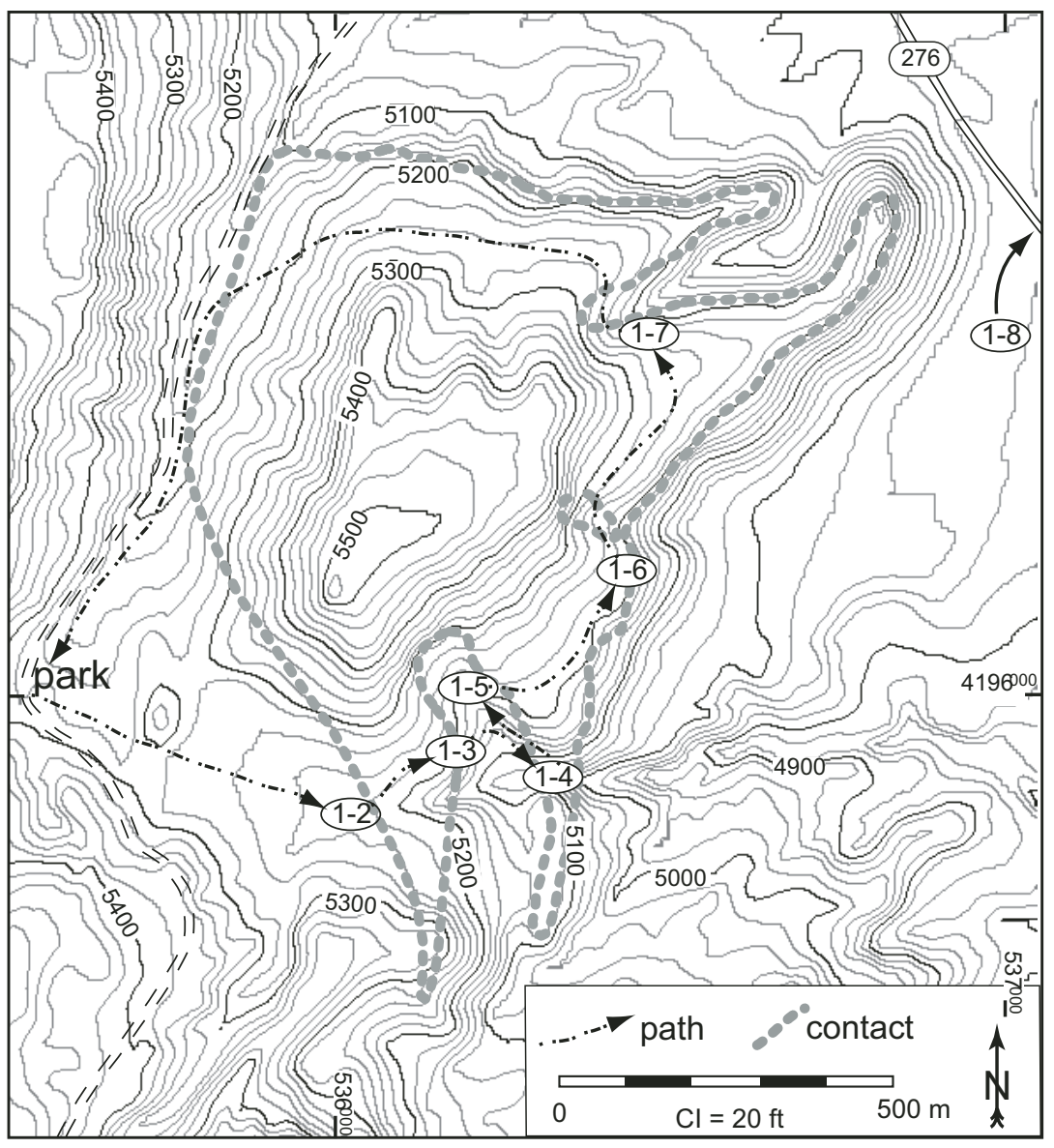

Figure 3. Topographic map of the Maiden Creek sill area with stops indicated. The dashed-dotted line shows the approximate path to be walked. parallel. These same observations will be seen on the margins of the Trachyte Mesa laccolith.

\section{Directions to Stop 1.3}

Head NE down the N side of the creek (Fig. 3) for $\sim 100 \mathrm{~m}$ until you are on relatively flat-lying sedimentary rocks. You should have an overview (looking S across the stream bed) of the $\mathrm{N}$-facing side of the stream canyon and $\sim 4 \mathrm{~m}$ high towers on the $\mathrm{N}$ side of the streambed.

\section{Stop 1.3: Lateral Terminations}

GPS (UTM): 536186, 4195897. Main points: (1) There are two bulbous terminations on the lateral margin of the sill, suggesting different magma sheets. (2) There is upward tilting of wall rocks on the margin of the intrusion. (3) This margin belongs to an NS-elongated part (finger) of the Maiden Creek sill.

Looking $\mathrm{S}$ from this vantage point, the lateral contact of the intrusion with the surrounding Entrada sandstone is beautifully exposed (Fig. 7A). The contact is complex; it is composed of two vertically stacked bulbous igneous terminations. As we will observe at other locations on the intrusion, this geometry is typical of most exposed lateral contacts of the Maiden Creek sill. We suggest that this geometry is most easily produced by the stacking of separate igneous sheets, and two separate sheets can be observed at Stop 1.8.

The relationships between the sedimentary host rock and the intrusion are better preserved at this location than at most others on the Maiden Creek sill. The sediments here tilt upward above each of the upward-facing portions of each bulbous sheet termination (Fig. 7A). This observation indicates that at least some of the host-rock displacement necessary for emplacement of the intrusion is accomplished through tilting of the sediments.

The lateral margin exposed here forms the eastern edge of a NS-elongated portion of the Maiden Creek sill (which we will refer to as a finger, following Pollard et al., 1975) that projects out from the main body of the intrusion. The ridge immediately E of here is defined by another NS-elongated finger. The lateral contact we have been considering and others in this area require that the current geometry of the fingers is very similar to the original emplacement geometry, i.e., these fingers were not formed by erosion of a once-contiguous sheet.

\section{Directions to Stop 1.4}

Head $(\sim 100 \mathrm{~m})$ ESE down to the streambed and continue through Secret Nap Spot gorge until you encounter a $10 \mathrm{~m}$ drop along the streambed. 


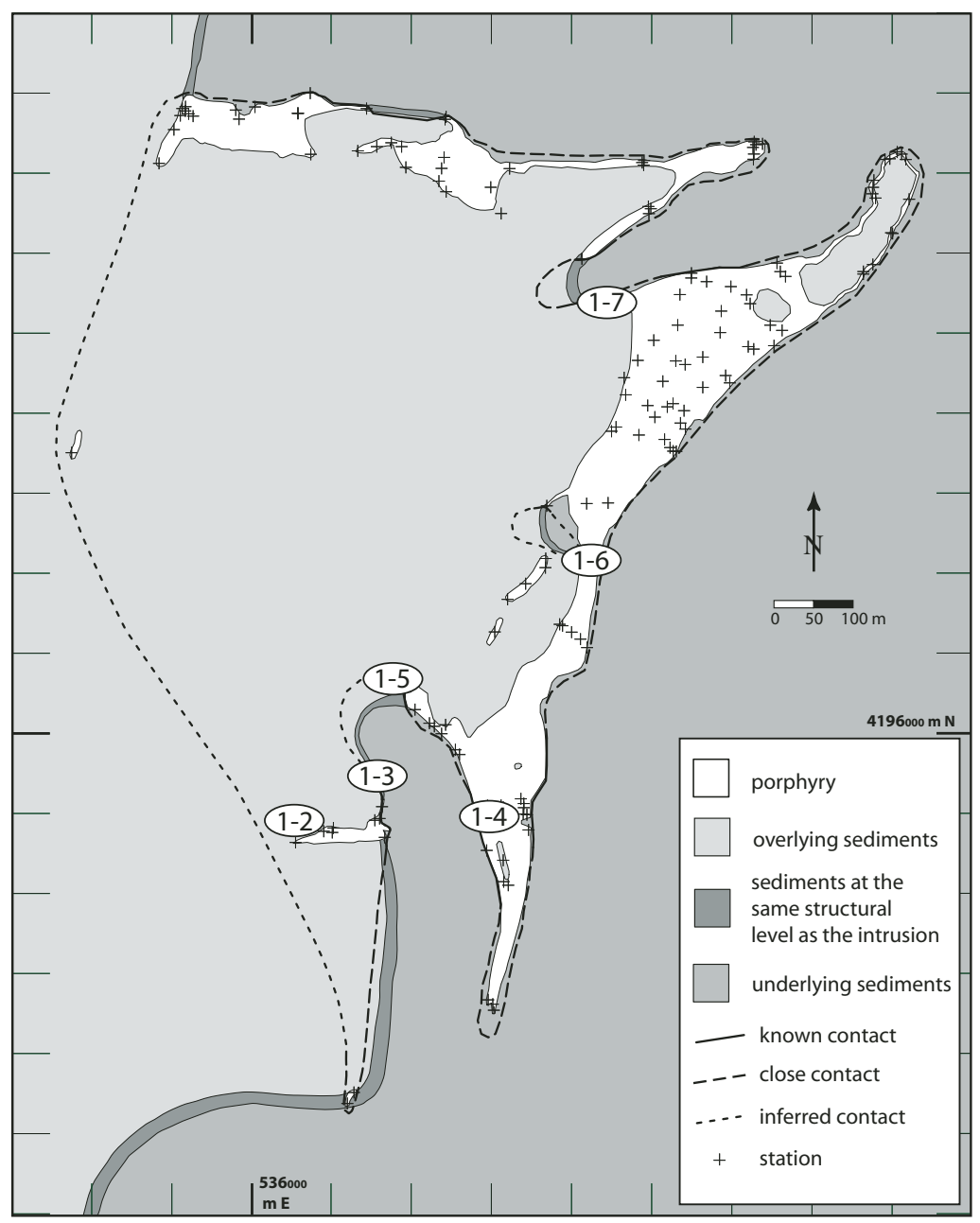

Figure 4. Geologic map of the Maiden Creek sill with stops indicated.

\section{Stop 1.4: Cross Section in Secret Nap Spot Gorge}

GPS (UTM): no GPS measurement is possible here. Main points: (1) Complete cross section of one finger. (2) Bottom contact is conformable and not deformed. (3) No stoping visible in the igneous rock.

Exposed at this stop is a complete cross section through one of the fingers of the Maiden Creek sill (E side of Fig. 5C). Although overlying sedimentary rocks are not clearly exposed atop the cliff faces here, they are in place nearby, as we will observe en route to a later stop. Examining the cliff faces, it is clear that there are no xenoliths of sedimentary rock within the intrusion. Sedimentary xenoliths are exceedingly rare in all of the intrusions we will be examining. This suggests that stoping is not an important space-making mechanism in these intrusions.

Also exposed here is the concordant horizontal bottom contact of the Maiden Creek sill with the underlying Entrada Sandstone (here a shale). The bedding in the host rock below the contact is essentially undeformed.

Clear evidence for three fingers (like this one) exists on the margins of the Maiden Creek sill and strong evidence for a fourth finger (which we were atop at Stop 2) exists. Preserved contacts demonstrate that the finger-like lobes project out from the main body of the intrusion and are not merely erosional remnants of a main body that was once larger and has been dissected by streams. No clear textural boundary exists between the main body of the intrusion and the finger-like lobes.

Each finger is $200-400 \mathrm{~m}$ long and is distinctly elongate with respect to both its cross-sectional thickness and map view width (Figs. 5A and 5B). In longitudinal cross section (Figs. 5C and $5 \mathrm{D}$ ), each finger thins progressively away from the main body. The finger shown in Figure 5A thins from $\sim 30 \mathrm{~m}$ thick near the main body to $\sim 7 \mathrm{~m}$ thick over a distance of $\sim 400 \mathrm{~m}$. This thinning occurs as the base of the intrusion cuts up through the sedimentary section while the top of the intrusion resides at a consistent bedding-parallel stratigraphic level.

\section{Directions to Stop 1.5}

Backtrack out of the gorge and then walk $\sim 175 \mathrm{~m} \mathrm{NW}$ up a smaller canyon developed in sedimentary rocks. Walk up the creek bed until igneous rock is encountered. 


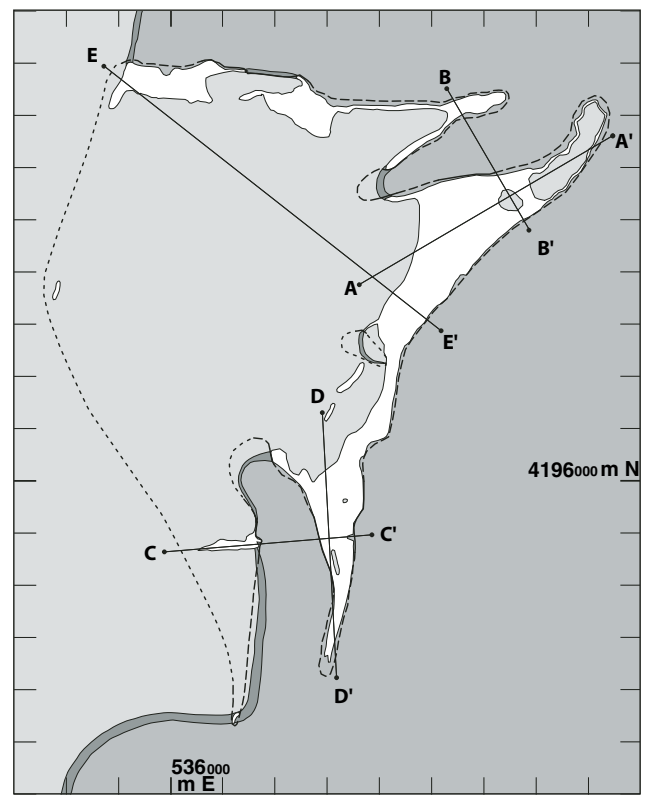

Figure 5. Cross sections of the Maiden Creek sill.

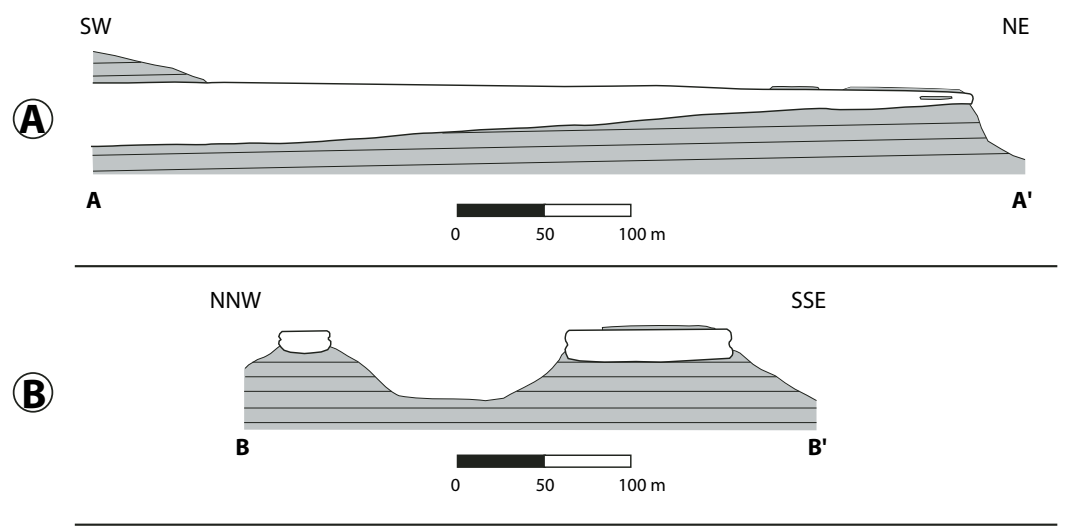

C

(D)

W

(C)

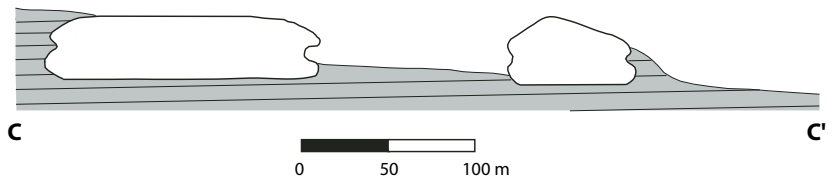

N

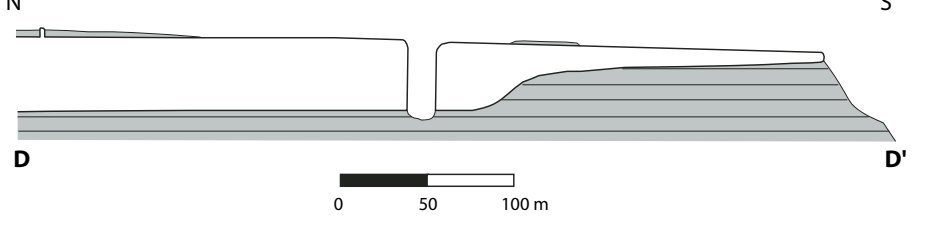

(E)

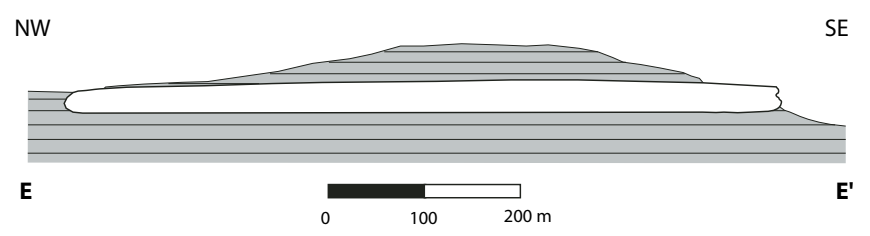

\section{Stop 1.5: Igneous-Sedimentary Contact on a Lateral Termination}

GPS (UTM): 536186, 4196016. Main points: (1) Solidstate deformation occurs locally on lateral contact. (2) Very little deformation or metamorphism occurs in wall rocks.

The lateral contact of the intrusion with the host rock is exposed at this stop. Solid-state fabric in the outermost few centimeters of the intrusion is prominently developed. In general, the solid-state fabric patterns are complex and probably reflect the nature of the emplacement process, which accommodated both lateral and vertical expansion and longitudinal propagation of the sheet. As we observed at Stop 1.2 atop the intrusion, fabric patterns at the top (and bottom) contacts tend to be more consistent and predictable than those observed at the lateral contacts. This difference is presumably related to the more complex flow present in the bulbous lateral sheet terminations than that present at the planar top and bottom margins of the sheet. Similar relationships are seen at Trachyte Mesa laccolith, i.e., intense deformation at the lateral margins and little to no deformation at the bottom and top margins.

\section{Directions to Stop 1.6}

Walk several hundred meters NE (Fig. 3) until cliff is encountered (edge of the intrusion). Notice along the walk the in situ horizontal sediments atop the intrusion.

\section{Stop 1.6: Geometry of Intrusion}

GPS (UTM): 536426, 4196131, Main points: (1) The Maiden Creek intrusion consists of 100-m-scale, finger-like intrusions that emanate from a central intrusion. (2) The top of the intrusion is relatively flat and concordant. The bottom of the intrusion cuts up-section, resulting in thinning of the intrusion along its length (longitudinal axis). (3) Bulbous terminations are stacked upon one another, on lateral margins of main part of the sill, suggesting that different magma sheets exist throughout the area of the intrusion. (4) Meter-scale topography exists locally on the top of the intrusion.

From this vantage point, much of the eastern side of the Maiden Creek sill is visible. We will discuss several noteworthy features of the intrusion. First, looking S from here, the southeastern finger of the intrusion (which we looked at in cross 

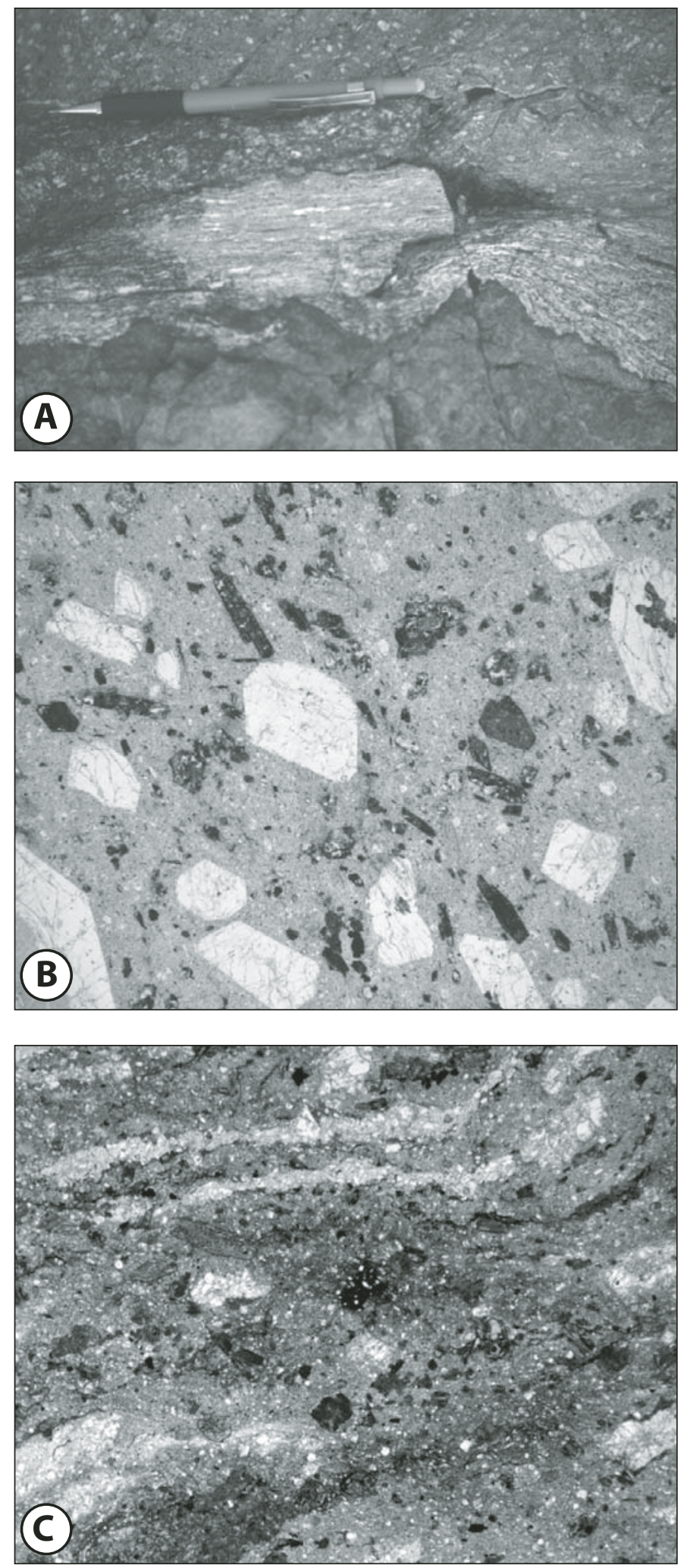

Figure 6. Microstructures in the Maiden Creek sill. (A) Field photo of solid-state fabric developed at contact. (B) Magmatic fabric. Photo is $\sim 1.5 \mathrm{~cm}$ across. (C) Solid-state fabric. Photo is $\sim 0.5 \mathrm{~cm}$ across. White streaks represent plagioclase phenocrysts that have been cataclastically altered to a much finer grain size and extended along the foliation. section at Stop 4) can be clearly seen. The top of the finger is relatively flat and concordant, and flat-lying sediments are still in place in several locations atop this part of the intrusion. Although not clearly visible from here, the bottom contact of the finger cuts up-section along its length, resulting in thinning of the intrusion. Each of the fingers of the Maiden Creek sill has a similar geometry.

These fingers radiate from the main body of the Maiden Creek sill, resulting in a complex map view geometry (Fig. 4). The main body of the intrusion (which we are now atop) is roughly elliptical in map view and has a relatively simple silllike geometry in cross section. This region of the intrusion is consistently $30-40 \mathrm{~m}$ thick. At least four separate, finger-like lobes project out from this main body. Each of these fingers is $\sim 30-40 \mathrm{~m}$ thick where it begins to project out from the main body and thins progressively to a thickness of $5-10 \mathrm{~m}$ as distance from the main body increases (Fig. 5). These fingers extend $200-400 \mathrm{~m}$ out from the main body of the intrusion and are distinctly elongate with respect to both their map view width and their cross-sectional thickness. The numerous extant lateral contacts with sedimentary host rock strongly suggest that the current map pattern (Fig. 4) of the intrusion is very similar to the original intrusive geometry. This complex geometry may be a common characteristic of sills in general (e.g., Marsh, 2004) because the lateral margins of most sheet intrusions are rarely as well preserved as those seen on the Maiden Creek sill.

Also visible from this vantage is the steep eastern side of the sill. Along this cliff the intrusion is $30-40 \mathrm{~m}$ thick and has two well-exposed vertically stacked bulbous lateral terminations (Fig. 7B). The lateral contacts with adjacent sedimentary rocks are locally preserved. As discussed earlier, these bulbous lateral terminations suggest that at least two magma sheets are stacked upon one another throughout the intrusion. These two sheets can be observed individually, as they thin to the NE and separate into individual sheets for several tens of meters (NE end of Fig. 5A; Stop 1.8). These intercalated sedimentary layers are observed in a few places and are dominantly found halfway between the base and the top of the sill, at the same location where the two bulbous terminations meet. Rare igneous-igneous contacts can also be traced from these screens of wall rock (Fig. 7C). These internal contacts are marked by a $1-2 \mathrm{~cm}$ zone of intense foliation and solid-state deformation. We will not visit the outcrop illustrated in Figure 7C, because one must climb down this cliff face, but we will see the two separate sheets from the road on Stop 1.8.

One final feature visible from here is the locally developed $\mathrm{m}$-scale topography of the top surface of the sill. Nascent dikes extending up from the roof of the intrusion occur in two places (one visible just $\mathrm{W}$ of here, the other on the NW exposed corner of the intrusion). Also present are m-scale ridges, generally oriented parallel to the strike of the edge of the intrusion. Johnson and Pollard (1973) interpreted similar ridges atop the Trachyte Mesa intrusion to record the position of the edge of that intrusion at various stages of progressive emplacement. 

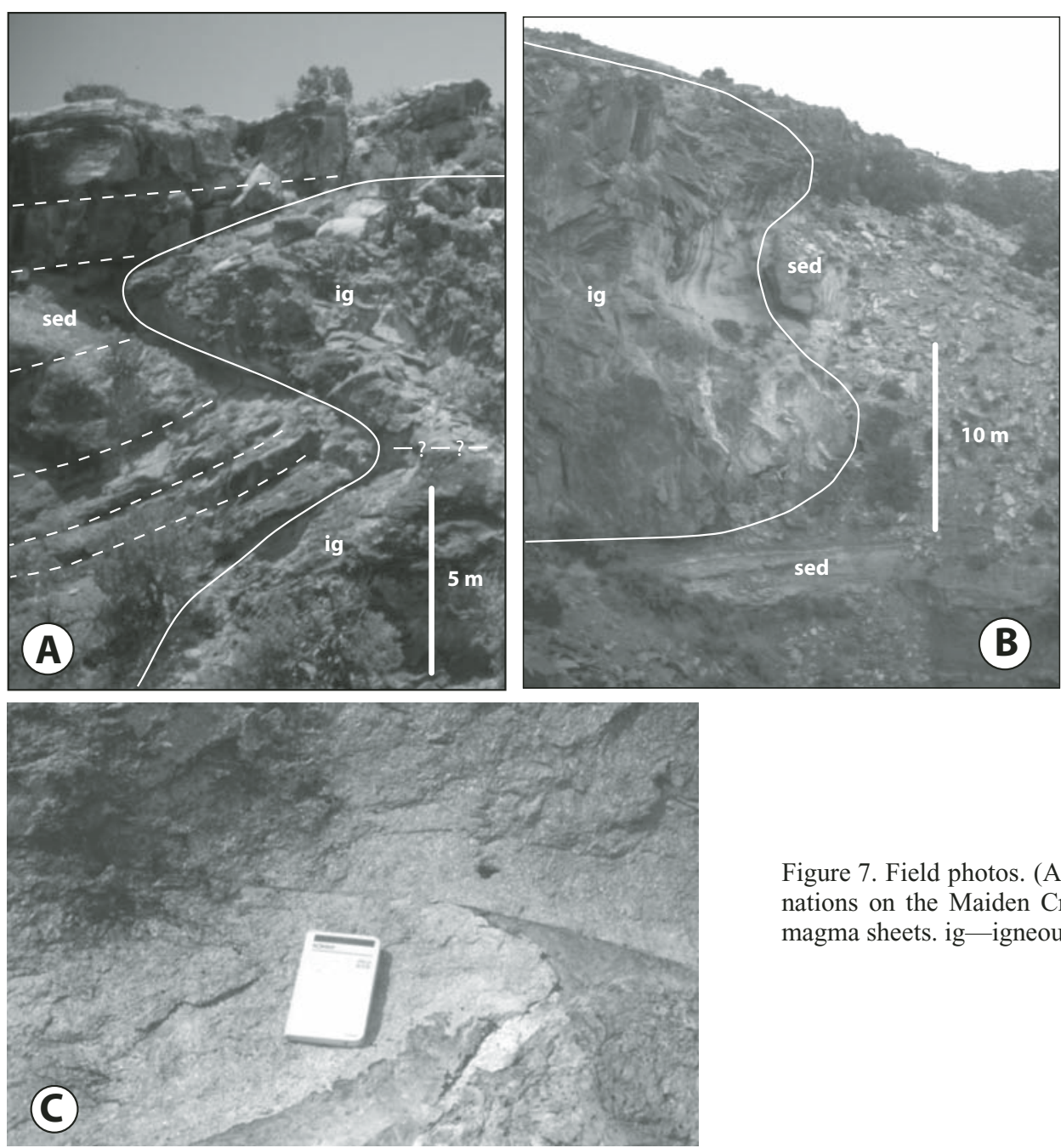

Figure 7. Field photos. (A, B) Annotated photograph of lateral terminations on the Maiden Creek sill. (C) Internal contact between two magma sheets. ig - igneous; sed—sedimentary.

\section{Directions to Stop 1.7}

Walk 200-300 m N, essentially on the top of the intrusion. Head for the overlook of a gully between two prominent NESW-oriented ridges (Fig. 3).

\section{Stop 1.7: Emplacement of the Maiden Creek Sill}

GPS (UTM): 536494, 4196351. Main points: (1) Magmatic flow is subparallel to the fingers. (2) Areal extent of the first sheet seems to have controlled the lateral extent of the second sheet. (3) Emplacement occurred primarily by upward vertical movement of the roof rocks although there are still space problems.

The gully below us to the $\mathrm{N}$ is bordered by two ridges, each of which is held up by a finger of the Maiden Creek sill. Excellent lateral contacts of both fingers are preserved at the SW end of this gully (see Figure 15 in Pollard et al. [1975] for a photograph of a portion of one of these lateral contacts).

Because we believe the current outcrop pattern corresponds to the original shape of the sill, an ideal opportunity exists to study the relationships between igneous fabric, emplacement processes, and intrusion geometry. Fabric results described here are summarized from Horsman et al. (2005), who used several techniques to analyze the fabric within the sill. Throughout the intrusion, solid-state fabric is confined to the outermost $\sim 3 \mathrm{~cm}$ of the intrusion (and the few internal contacts adjacent to the screens of wall rocks). At distances greater than $\sim 3 \mathrm{~cm}$ from the contact with the sedimentary host rock, magmatic fabric is almost exclusively developed. The boundary between the regions of solid-state and magmatic fabric is gradational over $1-2 \mathrm{~cm}$.

Magmatic fabric is a more reliable tool than solid-state fabric for studying magmatic flow during emplacement because the solid-state fabric records both magmatic flow and the interaction of the magma with the wall rock. Solid-state fabric is consequently more complex and difficult to interpret than magmatic fabric, which reflects primarily finite strain produced by the late-stage magmatic flow during emplacement (Horsman et al., 2005). With these caveats in mind, the fabric results for the Maiden Creek can be considered. 
Magmatic lineation in a finger of the sill is generally subparallel to the elongation direction of the finger (Fig. 8). Field-measured lineations and AMS (anisotropy of magnetic susceptibility) lineations are generally subparallel (for the details of the fabric and a discussion of the AMS see Horsman et al., 2005). Magmatic foliation in the fingers is generally sub-horizontal. Consistent magmatic fabric patterns are also observed in the main body of the sill, where magmatic lineation tends to be oriented roughly radial and foliation is generally subhorizontal. We interpret these patterns to record general flow of magma away from an unexposed source region to the $\mathrm{W}$ into the main body and then out of the main body and into each finger. Although, we cannot distinguish whether the fingers are late ancillary intrusions fed by the main body, or if the main body is a region that has coalesced into a sheet of magma by spreading between early fingers (e.g., Pollard et al., 1975).

We infer that the Maiden Creek sill consists of two separate, sequentially emplaced sheets that were emplaced as different pulses of magma. The two sheets have almost the exact same geometry and extent. Their similar cross-sectional geometry allows us to conclude that the pulses of magma were essentially identical in volume. This observation suggests that the emplacement and extent of the first sheet controlled the extent of the second sheet.

We envision the following scenario. The emplacement of the first sheet produces a weak, hot region surrounding the igneous body. During intrusion of subsequent igneous sheets, the adjacent heated sedimentary rock will be relatively weak and will fail before nearby cooler sediments. Consequently, after the emplacement of the first sheet, subsequent pulses of magma from the same feeder system intrude immediately adjacent to the previously intruded sheet. By this process, a thick sheet of igneous rock with a complex lobate three-dimensional geometry is built. The consequence is that the amount of magma intruding at any one time remains small.

Uplift of overlying roof rocks is the dominant space-making mechanism. However, when viewed in cross section, there does not seem to be enough deflection of the layers on the margins (layers that rotate up at the contact with the Maiden Creek sill) to accommodate the amount of vertical space required by the thickness of the sill. This observation indicates that other mechanisms, such as lateral displacement and strain of adjacent host rocks (as

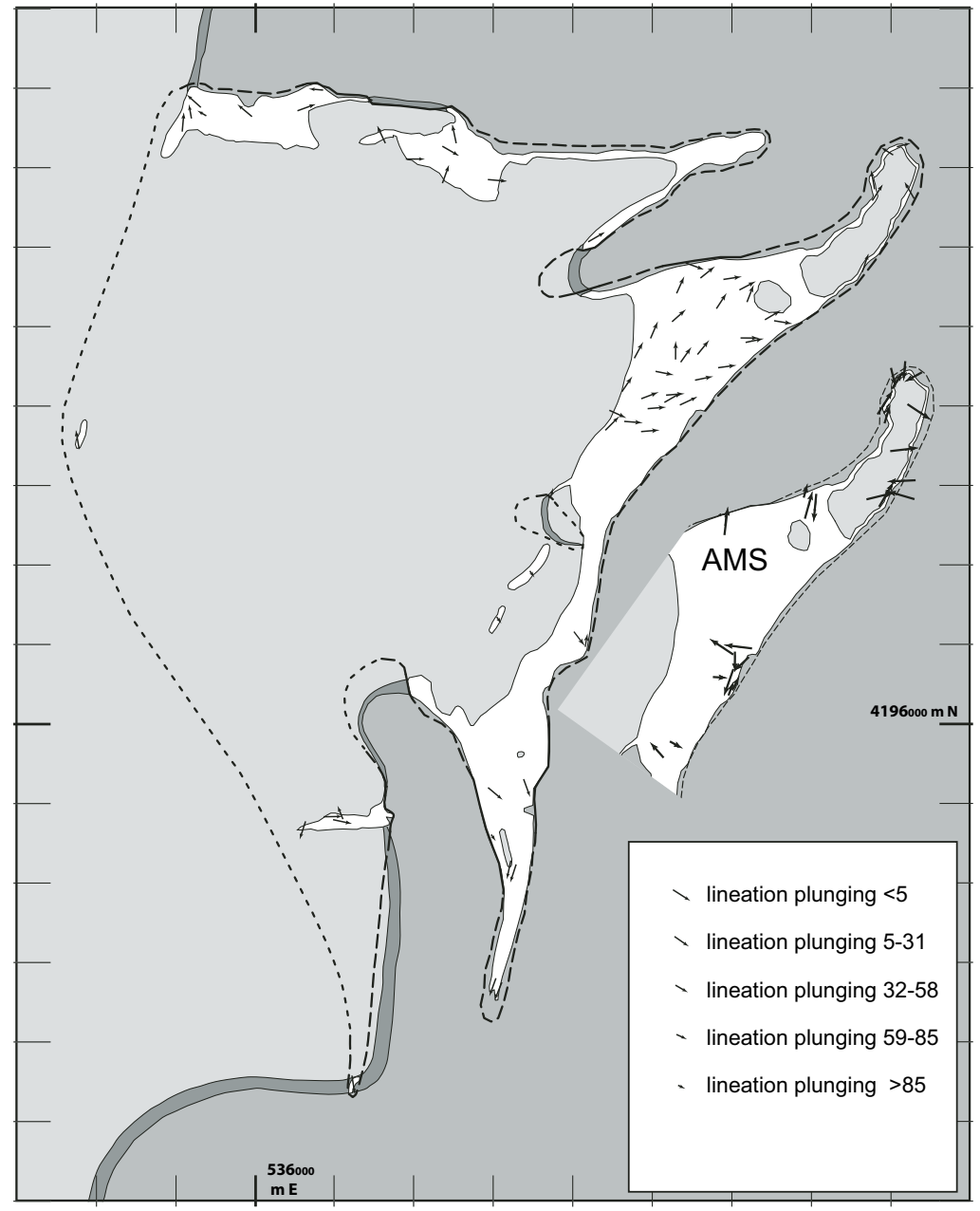

Figure 8. Macroscopic lineations and magnetic lineations (insert) on top of the Maiden Creek sill. AMS - anisotropy of magnetic susceptibility. 
we will observe at the Trachyte Mesa intrusion) may be responsible for some of the additional space making.

\section{Directions to Stop 1.8}

Head W (contouring) until the road is seen. Walk to road and then southward to car. Turn cars around and head back N and $\mathrm{E}$ on dirt road until intersection with Utah Hwy 276. Set odometer to zero and turn right (S) on Hwy 276. Drive $~ 0.6 \mathrm{mi}$ and park on the side of the road (Fig. 3). Look to the W toward the top of the mesa that terminates close to the road.

\section{Stop 1.8: Separate Fingers of the Maiden Creek Sill}

Main point: (1) Separation of the Maiden Creek sill into an upper and lower finger supports our model of two pulses of magma sheeting, one stacked upon the other.

Looking up at the top of the mesa, from the $\mathrm{W}$ to the $\mathrm{E}$, the NE finger of the Maiden Creek sill splits into an upper and a lower finger. These two thinner fingers extend for several tens of meters before terminating at the same lateral extent, and they both terminate along similarly oriented faults. A several-meter-thick, horizontal sedimentary block separates the two fingers (Fig. 5A). To the $\mathrm{W}$ of this intercalated sedimentary block, within the one thick (stacked) finger, a 2-3 cm thick, solid-state, igneous-igneous contact can be traced from the edge of the block for several tens of meters and define the boundary between the lower and upper fingers. Immediately to the $\mathrm{E}$ of the termination of these two fingers, another very thin sheet appears, at a topographic level intermediate between the upper and lower fingers and extends for several tens of meters before thickening at the margin of the mesa. We suggest that the separation of one thick finger into an upper and a lower finger, as well as the internal contact to the $\mathrm{W}$ of this split, supports our hypothesis that the Maiden Creek sill was constructed by stacking two sheets that share the same areal extent.

\section{Part II: Trachyte Mesa Laccolith}

\section{Directions to Stop 1.9}

Set odometer to zero. Turn around and head back $\mathrm{N}$ on Utah Hwy 276. At mile 1.6, just beyond (N) the rise in the road, turn left and drive SW onto a dirt road (Fig. 9). At mile 2.0, stop

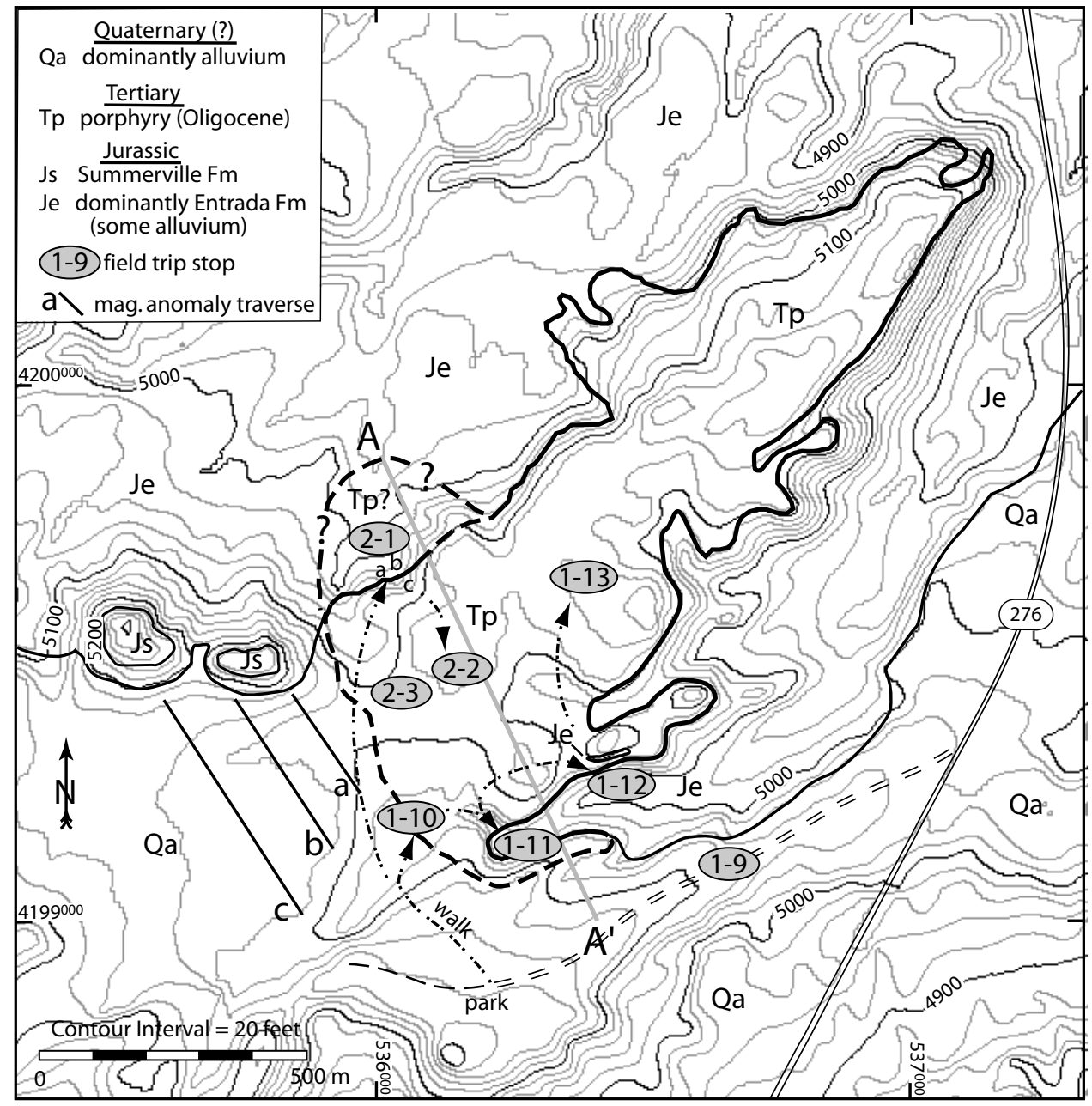

Figure 9. Topographic map of Trachyte Mesa laccolith with stops indicated. 
on the dirt road when it approaches within $\sim 40 \mathrm{~m}$ of a gully north of the road (Stop 1.9). Looking NW across the gully, there is a clear exposure of a meter-thick sandstone bed intercalated with igneous sheets at the top margin of the Trachyte Mesa laccolith.

\section{Stop 1.9: View of the Southeast Margin of the Trachyte Mesa Laccolith}

GPS (UTM): 536703, 4199129. Main point: Intercalated beds of Entrada Sandstone and igneous sheets within the margin of the Trachyte Mesa laccolith.

This is an excellent view of the sheeted nature of the Trachyte Mesa laccolith and the subhorizontal basal contact (Fig. 10). The cliff face below the intrusion is the red sandstone of the Entrada Formation. The thickest and lowest sheet of the Trachyte Mesa laccolith is $8 \mathrm{~m}$ thick here. Directly above this basal sheet is a 1$\mathrm{m}$-thick bed of Entrada sandstone. Directly above this sandstone layer are at least two more sheets. These two upper sheets have distinctively different erosional morphologies.

\section{Directions to Stop 1.10}

Continue SW on dirt road for $\sim 0.2 \mathrm{mi}$. Park at clearing by large juniper tree. GPS (UTM): 536254, 4198926. The road becomes less traveled beyond the juniper tree. At this point, the field trip will continue by foot. Head in direction 330 (azimuth) directly toward Bull Mountain (the last peak along the range moving toward the NE) on the E flank of Mount Ellen. Continue for $\sim 300 \mathrm{~m}$ until you intersect streambed. Walk downstream until the bed of the stream is igneous rock.

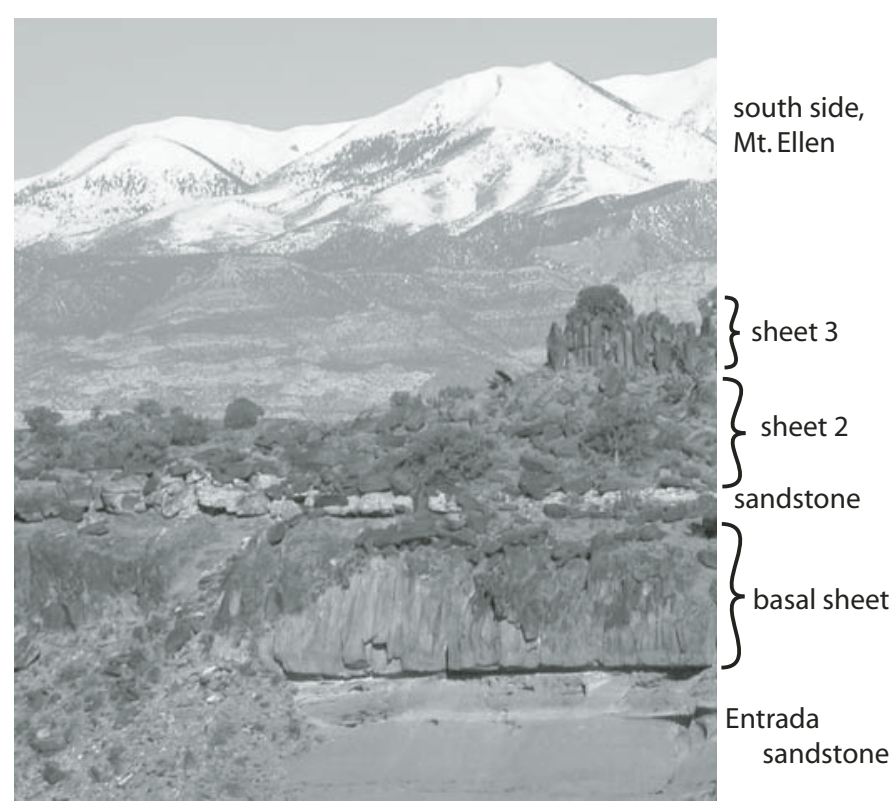

Figure 10. Photo of sandstone bed intercalated with igneous sheets, SE margin of Trachyte Mesa laccolith. Basal sheet is $8 \mathrm{~m}$ thick.

\section{Stop 1.10: Top Contact of the Trachyte Mesa Laccolith}

GPS (UTM): 536086, 4199194. Main points: (1) The composition and texture of the Trachyte Mesa laccolith is very similar to the Maiden Creek sill. (2) The upper igneous contact with undeformed and unmetamorphosed sandstone is well exposed. (3) The sandstone layer on the top contact here can be traced over much of the top of the laccolith.

This outcrop is assumed to be very close to the southern extent of the laccolith. The top contact is exposed and dips to the SW beneath sedimentary strata of the Entrada Formation. The thickness of the intrusion increases greatly from SW to NE along the streambed as the top contact rises $20 \mathrm{~m}$ over a lateral distance of $100 \mathrm{~m}$. The base of the intrusion is not exposed, but it is assumed to be very shallow $(<2-3 \mathrm{~m})$ beneath the southwesternmost exposure of igneous rock. We assume this because the basal contact is exposed to the NE, outside of the stream gorge, along the cliff that was viewed from the road driving in.

The top several $\mathrm{cm}$ of the contact of the Trachyte Mesa laccolith has been eroded at this location. At other locations where the actual top of the intrusion has not been eroded, there is a 2$3 \mathrm{~cm}$ thick carapace of solid-state deformation. Very limited (several $\mathrm{cm}$ or less) erosion occurred here, evidenced by the upper contact with the sedimentary rocks exposed on the hillside.

The texture and composition of the Trachyte Mesa laccolith is very similar to the Maiden Creek sill. The rock has a microgranular porphyritic texture with euhedral phenocrysts (up to $7 \mathrm{~mm}$ ) of hornblende and plagioclase. The groundmass consists dominantly of microlaths of plagioclase and oxides (mostly magnetite). Most of the plagioclase phenocrysts exhibit concentric zonation. Many of the hornblende phenocrysts and larger oxides are partially or completely altered to finer-grained oxides and calcite. A few pyroxene and apatite phenocrysts are observed.

The sandstone at the upper contact is unmetamorphosed and undeformed. Although, within several $\mathrm{cm}$ from the intrusion, we often observe pea-sized nodules within the sandstone that resist weathering. We can observe this feature here at the base of the sandstone layer. These nodules of sandstone have their pore spaces filled with calcite cement. Many of the oxides and hornblende in the igneous rock have also been replaced with calcite, documenting the fluids that passed through these rocks syn- to post-emplacement.

The sandstone layer is full of cm-scale holes and larger cavities. This spheroidal weathering seems to be a marker for this particular sandstone layer. We can trace this weathered $\sim 1$-mthick sandstone layer over the top of the Trachyte Mesa laccolith and over to the NW margin.

\section{Directions to Stop 1.11}

Walk downstream for $150 \mathrm{~m}$, through a gorge that turns to the $\mathrm{SE}$ and just past a $1 \mathrm{~m}$ drop in the creek bed and continue onto two large $(\sim 4 \mathrm{~m})$ boulders for an overview.

\section{Stop 1.11: Differential Erosion of Sheets}

GPS (UTM): 536236, 4199158. Main points: (1) There is geomorphic evidence for multiple intrusive sheets. (2) The 
sedimentary layer beneath the intrusion is a massive sandstone layer. (3) The basal contact is concordant and climbs upward to the SE because the sedimentary beds are tilted down to the NW.

The walls of the gorge we just walked through weather differently at different elevations. The upper part of the gorge, on both sides, is eroding and producing vertical cliff faces with multiple vertical joint faces. Approximately halfway down, both walls of the gorge step toward the center of the gorge. Several meters downward, the gorge walls become vertical once again. This differential erosion is best expressed on the $\mathrm{N}$ side of the gorge, where the jointing is also different between the top, middle, and bottom sections of the gorge walls. The middle section, which resists erosion and where there are very few joints, also increases in thickness gradually from the $\mathrm{W}$ to the $\mathrm{E}$ (down stream) and resembles a sill. We interpret this erosional profile as resulting from different igneous sheets. The differences in jointing within each "step" down the walls of the gorge are at least suggestive that these "steps" cooled at different rates or at different times. Basalt flows are routinely differentiated using differences in erosional profiles and differences in jointing. Cañón-Tapia and Coe (2002) were able to differentiate several different basalt flows along the Columbia River using AMS, which supported their identification of the flows based on textural, jointing, and erosional differences. However, we have found no textural evidence along the walls of this gorge for different sheets. Our AMS data (unpublished and not shown here), taken along multiple vertical profiles along the walls of this gorge, does not reveal any differences that may indicate distinct sheets.

At the E edge of the gorge, the stream cuts through the margin of the laccolith. Where the streambed changes from igneous to sandstone is a small $(<1 \mathrm{~m})$ cliff. Standing on the edge of the cliff, the basal contact is not exposed on the cliff wall below, but looking SE at the contact on the far cliff-face the basal contact is well exposed and much higher on the cliff face than your feet on the bottom of the gorge. The same abrupt rise in the base is observed on the distal parts of certain fingers of the Maiden Creek sill. Here, the contact is concordant and bedding is actually dipping $9^{\circ}$ to the NW. This NW dip to the bedding is consistent with the observation that the NW margin of the Trachyte Mesa laccolith is several tens of meters lower, topographically, than the SE margin. The top surface of the NE half of the Trachyte Mesa laccolith also dips to the NW. The top surface of the Trachyte Mesa laccolith in the SW has a relatively flat top.

This massive sandstone layer found beneath the contact is observed wherever the basal contact is exposed. The base of the Trachyte Mesa laccolith is exposed around most of the SE margin and in a few places around the NW margin. Because the 1-m-thick sandstone layer is usually observed at the upper contact (except for Stop 1.12), and the massive sandstone layer is always found at the base, we believe the Trachyte Mesa laccolith is largely emplaced at the same stratigraphic level throughout its extent.

Position yourself on the edge of the small cliff again and again look SE at the far cliff face. The top contact is also exposed on the cliff face and reveals a much thinner part of the Trachyte
Mesa laccolith than in the gorge. This part of the Trachyte Mesa laccolith is actually a NE-oriented finger, one of four such fingers along the SE margin. We will view the termination (cross-sectional view) of this finger from Stop 1.12.

\section{Directions to Stop 1.12}

Head back upstream toward Stop 1.10, but turn $\mathrm{N}$ up a tributary gorge after $\sim 40 \mathrm{~m}$. Head $\sim 50 \mathrm{~m}$ up this gorge until you are on the top of the Trachyte Mesa laccolith. Walk ENE toward $075^{\circ}$ for $\sim 250 \mathrm{~m}$ to the cliff that marks the SE extent of the mesa. Find the only place along the cliff-face where you can scramble down several meters without scaling the cliff. You will also find 1-m-thick blocks of sandstone along the top edge of the cliff face here. This is the cliff face we saw from Stop 1.9 (on the dirt road coming in) that has sandstone between sheets of the Trachyte Mesa laccolith.

\section{Stop 1.12: Sheets, Fingers, and Intercalated Sandstone along the SE Margin of the Trachyte Mesa Laccolith}

GPS (UTM): 536322, 4199495. Main points: (1) This margin of the Trachyte Mesa laccolith is composed of several sheets. (2) Early sheets are full of cataclastic bands and may be a result of the emplacement of later sheets, which are undeformed. (3) The contact between sheets is marked by a thin, solid-state shear zone. (4) The sheets erode differentially here, producing an irregular erosional profile. (5) The 1-m-thick sandstone layer, usually found at the top contact, is intercalated with thin igneous sheets near the top of the mesa. (6) Looking across the valley to the SW, we see the end of the fingers that we saw from the side at Stop 1.11. These fingers are similar in shape to the ones observed at the Maiden Creek sill.

Immediately SW of the sandstone blocks that are intercalated with higher level sheets, scramble down the margin several meters. Look SW at an irregular cross-sectional view of the rocks that make up the top-margin of the mesa here. Figure 11 is a photo of these rocks and outlines the borders of the sheets as they form the margin of the mesa. The middle sheet is $\sim 1 \mathrm{~m}$ thick and undeformed. The top and bottom contacts are marked by a 2-cm-thick solid-state shear zone of intense foliation defined by aligned plagioclase crystals that are cataclastically crushed and elongated. These contacts between these sheets can be traced for at least $100 \mathrm{~m}$ to the SW. The sheets below and above are full of cataclastic bands that do not cross into the middle sheet. This brittle deformation suggests that emplacement of this middle sheet involved high strain and/or emplacement rates or that the magma already there had crystallized to a greater degree than the incoming sheet. In either case, the deformation supports forceful emplacement of the middle sheet. Clues to the mechanisms of forceful emplacement will be observed at Stop 2.1.

Scramble up to the top of the cliff again and walk several meters NE to examine the 1-m-thick sandstone blocks intercalated between sheets. Note how they are undeformed and unmetamorphosed and resemble the sandstone layer on the top contact observed at Stop 1.10. This may indicate the although 
most of the laccolith was emplaced at the same stratigraphic level (just below this sandstone layer), some thin higher-level sheets were emplaced just above this sandstone layer.

Look to the SW, across the valley below, at the southernmost finger that extends toward the NE (obliquely toward the viewer). Erosion reveals a cross-sectional view of this finger, which resembles two fingers side-by-side in shape (Fig. 12). Sedimentary wall rocks are immediately to the left (SE) of this "double" finger. The shape of these fingers resembles the fingers at the Maiden Creek sill. Approximately $15 \mathrm{~m}$ to the $\mathrm{N}$ of this exposure is another finger extending along the same trend (NE), but this finger is thinner. The link from this finger to the "double" finger is unclear.

\section{Directions to Stop 1.13}

Walk due $\mathrm{N}$ for $\sim 400 \mathrm{~m}$ to a small rise in the center of the Trachyte Mesa laccolith where there is a view of the NE half of the laccolith.

\section{Stop 1.13: Plateaus (Sheets?) on Top of the Trachyte Mesa Laccolith}

Main point: (1) The top of the Trachyte Mesa laccolith is composed of several plateaus. We suggest that these plateaus may be magma sheets.

The top of the Trachyte Mesa laccolith is characterized by a series of small-scale plateaus and ridges. On the scale of the intrusion, these features are small irregularities on a relatively flat surface. On the outcrop-scale, relatively flat areas (hundreds of square meters) are often terminated by an escarpment, which rises up several meters (or less) to the next plateau or defines an elongate ridge. Ridges can be curved or straight and are continuous for several hundred meters.

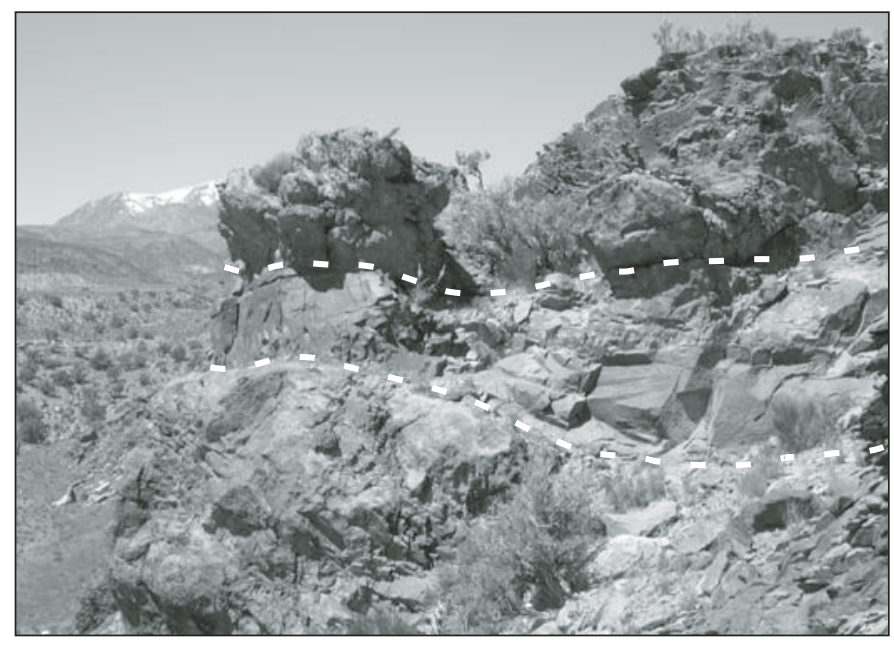

Figure 11. Sheeted outcrop at Stop 1.12. The sheet outlined by the dashed line is undeformed and $1 \mathrm{~m}$ thick. The surrounding sheets are cut across by abundant brittle faults. A $1-2 \mathrm{~cm}$ thick, solid-state shear zone marks the boundary between sheets.
Looking to the NE from Stop 1.13, we can identify two main plateaus that shape the top of the NE half of the mesa. Looking to the ENE, the first plateau is slightly lower in elevation and ends at the SE margin of the mesa. There is very little vegetation and abundant exposure of flat igneous rock. This surface is slightly dipping to the NW. Moving to the NNE, a small (1-2 m) cliff defines a slightly higher, second plateau. Both of these plateaus can be traced to the NE, where they become more narrow and then further to the NE more expansive again. We suggest that these plateaus may represent individual magma sheets because their dimensions are sheet-like and they terminate along steep margins, similar to the terminations of known sheets (with wall rocks) at Maiden Creek sill. Some plateaus even terminate in bulbous margins.

\section{End of First Day}

Walk SE back toward Stop 1.10 and return to vehicles. Drive $\sim 0.5 \mathrm{mi} \mathrm{NE}$ on dirt road toward Hwy 276. Turn left on Hwy 276 and drive N 5.8 mi to Hwy 95. Turn left on Hwy 95 and drive 26 mi NNW back to Hanksville.

\section{Day 2: Trachyte Mesa Laccolith (continued), Black Mesa Bysmalith, and Sawtooth Ridge Intrusions}

In the morning we will continue examining the Trachyte Mesa laccolith with a detailed look at the NW margin and in the afternoon examine the SE margin of the Black Mesa bysmalith and an overlook of the Sawtooth Ridge intrusion.

\section{Directions to Stop 2.1}

We are driving to the same location as yesterday afternoon. Starting in Hanksville, drive $26 \mathrm{mi}$ S on Utah Hwy 95. Turn right

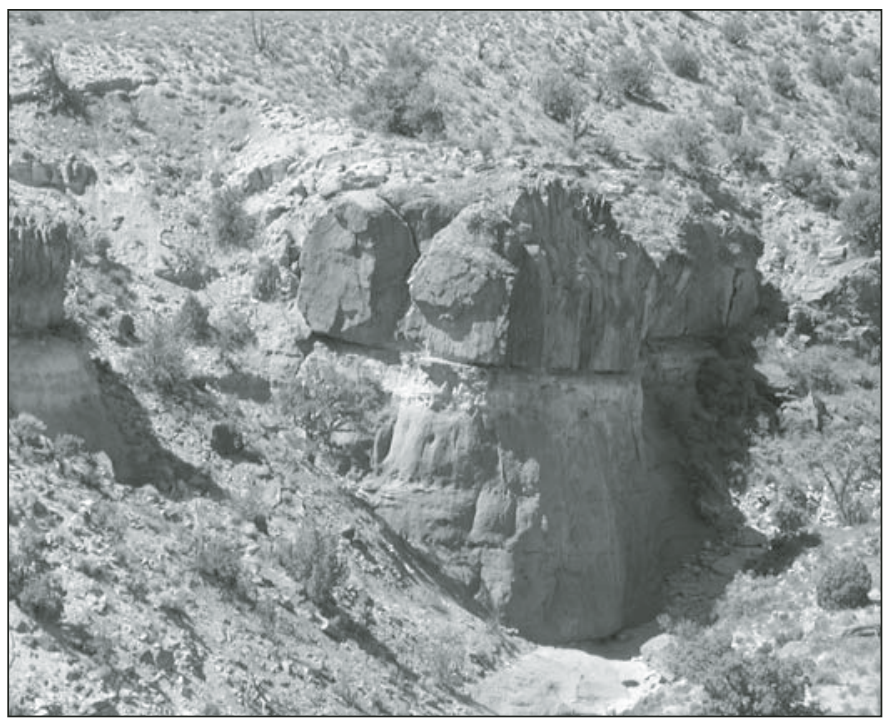

Figure 12. Photo of two magma fingers, side-by-side at Stop 1.10 taken from Stop 1.12. 
onto Utah Hwy 276 toward Ticaboo and reset the odometer. At mile 5.7 , turn right onto a dirt road and drive $\sim 0.5 \mathrm{mi}$. Park at a clearing by large juniper tree where the road becomes less traveled.

Walk in a $350^{\circ}$ direction for $\sim 500 \mathrm{~m}$ toward the NW margin of the mesa. At the edge of the mesa you will find a basin that opens to NW, and you will have a cliff below you. Avoid the cliff in front of you and carefully make your way down, bearing to the SW until you are $\sim 1 / 3$ of the way down, and you will have an overview, looking to NE, of a thick $(6 \mathrm{~m})$ continuous red sandstone bed, which rises up onto the top of the intrusion. You should be standing on igneous rock.

This is a very informative but complex outcrop, and there are several stops here. The basal and top contacts of the Henry Mountains intrusions are often observable, but this is one of the few locations in the Henry Mountains (and the only location on the Trachyte Mesa laccolith) where the wall rocks are preserved, well-exposed, and easily accessible as they are rotated upward to become the roof of the intrusion. There is also evidence for sheeting at this location and evidence for the relative timing of sheet emplacement and associated deformation.

\section{Stop 2.1a: Overview of Lateral Termination}

GPS (UTM): 536029, 4199604. Main points: (1) Geometry of the lateral termination of the intrusion. (2) There are sill-like sheets and tongue-like sheets exposed here.

The edge of the laccolith is superbly exposed here. At all other margins of the Trachyte Mesa laccolith, we assume the edge of the mesa is close to the actual termination of the laccolith, but this is only an assumption based on the shape of the margin (in many places the termination is bulbous). The thickness of the Trachyte Mesa laccolith is $43 \mathrm{~m}$ here, which is probably close to the maximum thickness. The valley floor is at the approximate level of the base of the intrusion. The top of the intrusion is composed of at least two, and possibly three sill-like sheets here (Fig. 13). We differentiate between sill-like sheets, which extend for tens of meters in two dimensions and are a maximum of three meters thick, versus tongue-like sheets, which resemble a tongue in shape and are only exposed at the base of the laccolith here.

Looking NE, sill-like sheets extend from the top of the mesa (in the SE) to beyond the edge of the mesa and rotate downward and form the actual NW margin of the intrusion.

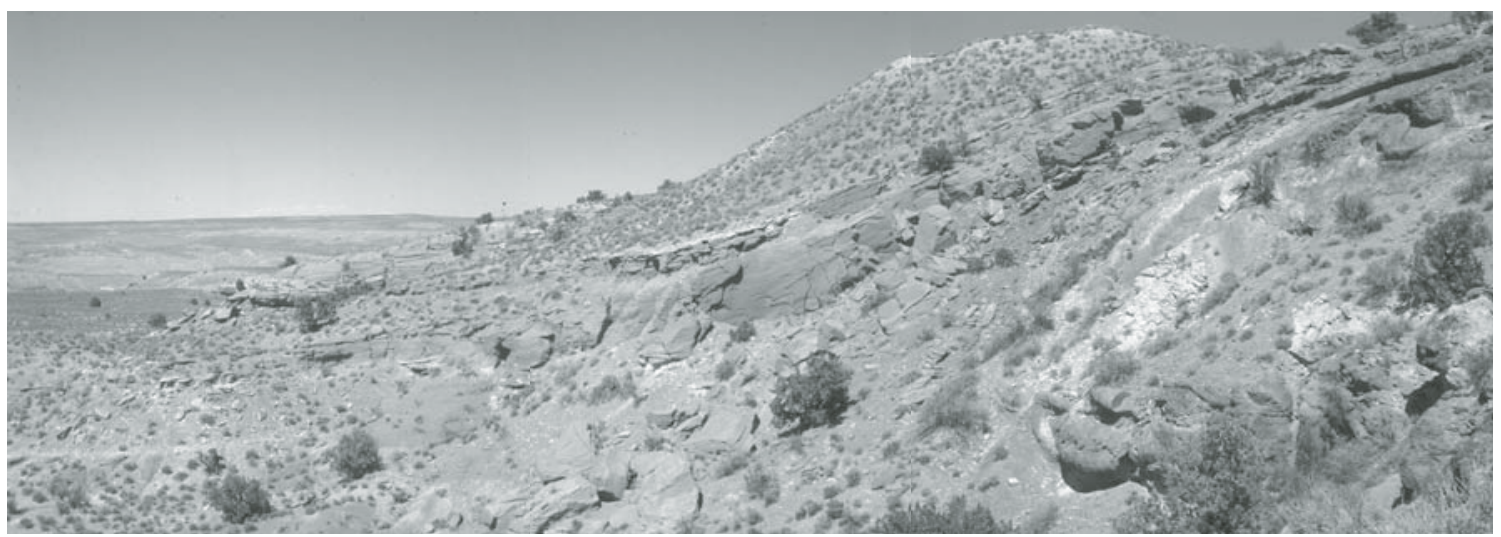
NW

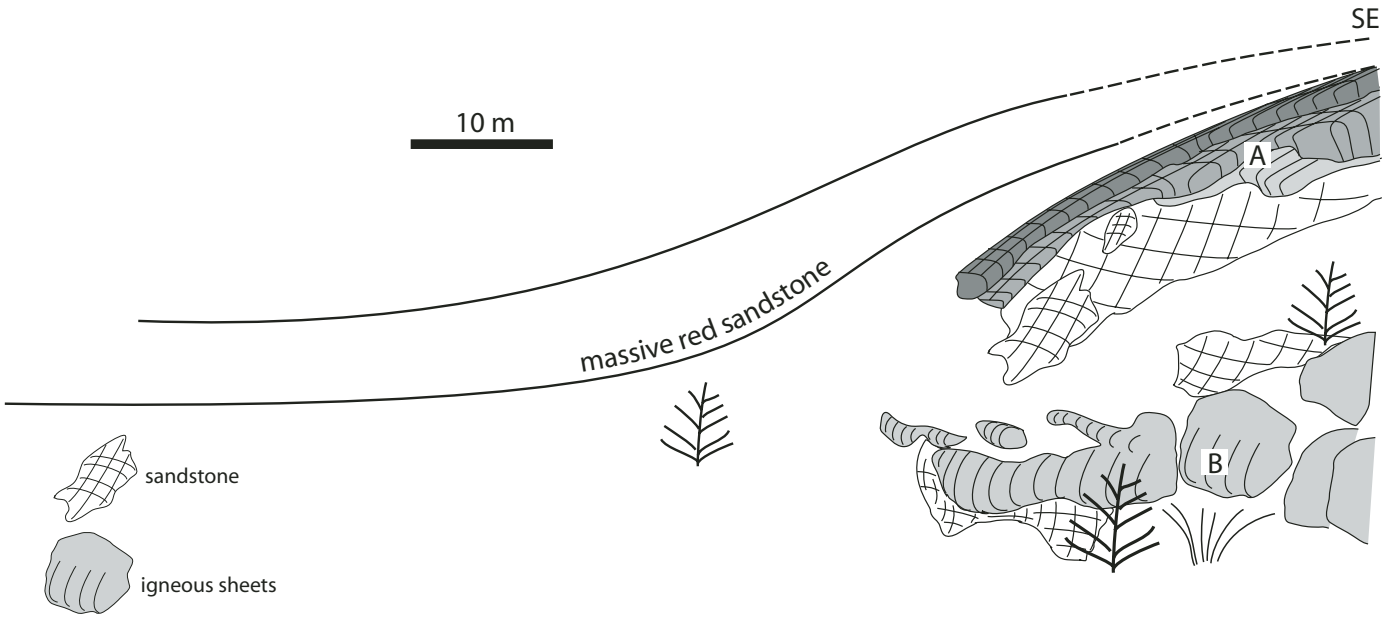

Figure 13. Photo and line drawing of Stop 2.1b and 2.1c at the NW margin of Trachyte Mesa laccolith where wall rocks are preserved as they rotate upward and onto the top of the laccolith. At A, there are three stacked sill-like sheets exposed. At B, tongue-like sheets are exposed. Igneous rocks are shaded. 
Most of the top sheet abruptly terminates $\sim 1 / 4$ of the way down the margin. The top sheet is $\sim 50 \mathrm{~cm}$ thick and the termination is not tapered, but wall-like (the front surface is perpendicular to the top surface of the sheet). We assume the shape of this sheet is not erosional, but actually represents the true shape of the sheet because the thin $(2-3 \mathrm{~cm})$ cataclastic carapace is preserved in many places along the top and wall-like frontal face. Further down the margin, the middle sheet (below the top sheet) continues until $\sim 1 / 3$ the way down to the valley floor and the slope of the margin becomes steeper. This sheet is irregularly eroded and is $<1 \mathrm{~m}$ thick. The bottom sheet is also thin $(<1 \mathrm{~m})$ and extends slightly further down the slope. The bottom sheet may be part of the overlying (middle) sheet. In the middle third of the slope, there are sandstone layers concordant to the top of the lowest sheet with a dip-slope of $\sim 65^{\circ}$. These sedimentary beds continue to the valley floor as a dip-slope. Note that the white colored sandstone layer is full of cm-scale holes and larger cavities similar to the sandstone layer at Stop 1.10, on the SE margin, although the sandstone layer is thinner here, possibly as a result of strain. This sandstone layer comprises the inner part of the contact zone.

The bottom third of this margin is composed of the sandstone beds discussed above, but they are sharply cut by tonguelike igneous sheets. These tongue-like sheets are subhorizontal and are exposed for a maximum of several meters as they protrude outward from the sandstone dip-slope. The frontal margins of these sheets are bulbous and some form perfect hemispheres whereas some are more rectangular. Below these tongue-like sheets the sandstone layers continue to dip at high angles $\left(60-70^{\circ}\right)$, but they are intensely deformed by multiple faults and currently erode into $\mathrm{cm}$-scale blocks and slivers. Thin selvages of these cataclastically deformed sandstones are found on the frontal margins of some tongue-like sheets where they are even more intensely faulted and sheared.

Twenty to $30 \mathrm{~m}$ to the NE, a $\sim 6$-m-thick massive red sandstone layer can be seen as it rises up from a relatively flat-lying position in the NW to become the top of the intrusion in the SE (Fig. 13). This sandstone bed rises up over the igneous sheets discussed above and comprises the outer part of the contact zone. Below this massive sandstone layer is a 3-m-thick series of thinner sandstone and shale beds. At the base of this 3-m-thick series is a $50-\mathrm{cm}$-thick sandstone bed that marks the inner contact zone. The actual contact with the intrusion is intensely sheared and faulted, and there are bedding plane faults between most or all of the different sedimentary layers here. The intrusion is also intensely sheared at the contact here and locally pieces of sandstone and porphyry are mixed and sheared into a fine grained, intensely foliated rock.

It is important to note that the sandstone beds at the immediate contact with the laccolith, in the middle portion of the slope, have a much higher dip than the massive red sandstone does on the outer part of the contact. We suggest this attests to the resistance to bending of the thicker, and possibly stronger, massive sandstone bed and leads to a space problem between the two layers. This space problem results in the emplacement of the tongue-like sheets and will be discussed later.

The entire hillside you are standing on, which defines the edge of the mesa here, is a composite of many subhorizontal silllike igneous sheets. Most of the igneous rock (and thus most of the internal contacts) is covered by a manganese oxide coating. The irregular shape of the slope often defines the sheets. Look for areas of exposure along ridges and bumps that might be contacts. These sill-like sheets can be traced for many meters laterally and seem to about one $\mathrm{m}$ thick with a maximum thickness of 2-3 $\mathrm{m}$. Contacts between sheets are $2-3 \mathrm{~cm}$ wide and are defined by a strong foliation containing highly elongated and shattered plagioclase phenocrysts that are parallel to the subhorizontal sheets. Some sheets are deformed by abundant cataclastic bands; some sheets are undeformed. These observations are similar to the deformation observed surrounding the sheet at Stop 1.12. There does not seem to be any order to the sequence in which the sheets have intruded. Based on the assumption that undeformed sheets are later than deformed sheets, later sheets intrude at various levels within the stack.

In summary, an entire cross section of the contact is revealed here. We are standing on the most inner portion, where sheets are stacked. As we move 20-30 m to the NE, the sedimentary layering at the inner contact is exposed and has been rotated to high angles by the stacking of the sheets. Moving another 10-20 m NW, the outer part of the contact is exposed where a thicker sandstone layer is rotated upward and onto the top of the intrusion.

\section{Directions to Stop $2.1 \mathrm{~b}$}

Continue to carefully hike down the slope to the valley floor. Walk to the NE to examine the tongue-like sheets protruding through the sandstones at the base of the cliff discussed above.

\section{Stop 2.1b: Late Stage Magma Tongues}

Main points: (1) Sheets at the valley floor are tongue-like in shape. (2) These tongue-like sheets intrude through inclined (not flat-lying) sedimentary rocks and indicate that these sheets are late. (3) Sheets have bulbous shapes to their margins.

These tongue-like sheets protrude through and deform the inclined sandstones that form the margin of the laccolith here (Fig. 13). This indicates that these sedimentary layers had already been rotated to their presently inclined position prior to being intruded. Because these inclined sandstones mark the lateral termination of the laccolith, these tongue-like sheets are viewed as being very late in the emplacement of the Trachyte Mesa laccolith (they postdate the formation of the lateral termination). In contrast, the sill-like sheets on top are concordant to the sandstone that represents the margin, and therefore we believe those sill-like sheets represent the earliest emplacement of magma at this margin. The sedimentary rocks below the tongue-like sheets are intensely faulted and the lateral margins of some of these sheets are also marked by faults. The bulbous margin of some of these tongue-like sheets indicates they are exposed very close to their outer contact. 


\section{Directions to Stop 2.1c}

Walk $20-30 \mathrm{~m}$ to the NE toward the massive red sandstone. Hike up the talus-covered slope between the exposed sheets to the SW and the red sandstone to the NE until you can walk onto the upper igneous sheets. You are almost at the top of the mesa here.

\section{Stop 2.1c: Early Sheet Intrusion and Deformation of Overlying Sedimentary Rocks}

GPS (UTM): 536075, 4199631. Main points: (1) There is intense solid-state deformation of the upper $2-3 \mathrm{~cm}$ of the silllike sheets and magmatic textures beneath. (2) The sill-like sheet intrusions are early and tilted and their slickensided surfaces exhibit evidence for late slip by subsequent intrusion. (3) There is intense brecciation of the sandstone bed immediately at the contact. (4) Flexural slip occurs on bedding planes and igneoussedimentary contacts. (5) Thinning of the massive red sandstone bed is accommodated on the grain-scale (grain size reduction and porosity collapse).

Below the slickensided polish, the uppermost contact of these sheets exhibits a 2-3-cm-thick zone where the plagioclase crystals are intensely fractured, and in places completely shattered into micron-scale pieces, and these pieces were dragged along the foliation. On a macroscopic scale, the very fine grain size of the plagioclase pieces defining the foliation can be easily misinterpreted as ductile deformation of the plagioclase grains. On the surface, these pieces of plagioclase are dragged to form the obvious lineation that trends NW, perpendicular to the margin here. Shattered plagioclase grains have also been flattened to form a foliation, but the lineation is much stronger than the foliation, similar to the magmatic fabric found throughout the main body of the intrusion.

The top surfaces of the sill-like sheets on the margin here are composed of thin $(<1 \mathrm{~cm})$, green (chlorite?), very fine grained, striated, polished surfaces forming the contact between the sheets and the sedimentary cover. This low-grade slickensided surface suggests that these upper sheets were emplaced early in the emplacement of the Trachyte Mesa laccolith, and were subsequently uplifted, rotated, and sheared during flexural slip along contacts by later emplacement of the main body of the intrusion below. Supporting this hypothesis is the observation that the sedimentary layers below these sheets are also rotated into the same inclined position, presumably by the igneous mass behind them. The other possibility is that these sheets intruded late, but followed bedding planes. In this case, as the bedding rotates downward at the margin, sheets followed bedding and intruded downward as they encountered the already formed margin.

The sedimentary layers above the contact are deformed to varying degrees. Immediately above the contact, a 50-cm-thick sandstone layer is faulted and locally intensely brecciated. Some of this deformation might be related to the early emplacement of the top sheet, which terminates abruptly at this location, or it might be due to the later emplacement and inflation of the main igneous mass. There are faults between most (or all) of the sedimentary layers between the contact and the massive red sandstone layer, suggesting that flexural slip has occurred to partly accommodate the upward rise and rotation of these layers. Immediately at the contact, the intrusion is also intensely sheared, but only for the top few $\mathrm{cm}$. Approximately one-third the distance down the margin there is a zone of mixed sedimentary and igneous rock (top sheet) that is intensely sheared. Shear bands that cut across the foliation indicate that the sedimentary rocks were moving up and over the intrusion to the SE.

Detailed two-dimensional strain analysis (normalized Fry analyses) was completed on 32 sandstone samples taken from massive red sandstone layer (Fig. 14), which is a high-porosity $(>10 \%)$ sandstone. Strain ratios generally increase toward the middle and upper portions of the massive red sandstone layer and then slightly decrease at the top. Two-dimensional porosity data was also collected on most of the same samples. Porosity data was collected from photographs of grains by using a graphics program whereby the area of the pore spaces versus the area of the grains could be differentiated.

The thinning of the massive red sandstone is a result of grain fracturing and grain sliding, which induce a porosity decrease. In Figure 14, there is a correlation between the increase in strain ratios and the decrease in porosity along the massive red sandstone layer. Microstructurally, there is a qualitative increase in fractures as porosity decreases and strain ratios increase. Fractures mostly emanate from grain contacts and in the highly attenuated part some grains are completely crushed. Crushed grains are not observed from samples at the NW end of the layer. We associate all of this deformation to emplacement of sheets and subsequent vertical inflation of the laccolith. The observation that the strain decreases as the sandstone rolls over on to the top of the intrusion is inconsistent with the "rolling hinge" model of Hunt (1953). In this model (one of three Hunt proposed for emplacing laccoliths) an already thickened intrusion advances laterally as sedimentary rocks are rolled up and over the front of the advancing massive sheet.

\section{Return to Stop 2.1a: Evolution of a Lateral Termination}

Figure 15 is our interpretative cross section of the margin at Stop 2.1. We envision an incremental emplacement model for the Trachyte Mesa laccolith whereby vertical growth occurs through stacking of magma sheets. All the sill-like sheets stopped their lateral migration at generally the same location, similar to our observations at the Maiden Creek sill. There is one outcrop of a thin sheet located $\sim 130 \mathrm{~m} \mathrm{~N}$ of the base of the mesa here, and this is why we place the lowermost sheet on our cross section. There does not seem to be any order to the vertical sequence of the sheets, except that the earliest sheets have been lifted to the top of the pile (the sill-like sheets that "drape" over the margin). The vertical stacking of sheets causes the mechanically strong massive red sandstone at the marginal contact to bend upward and results in a low-pressure triangle-shaped zone at the base of and in front of the marginal contact. The low-pressure zone is created because the more massive sandstone layer is thick and strong and resists bending, and therefore does not conform exactly to the 


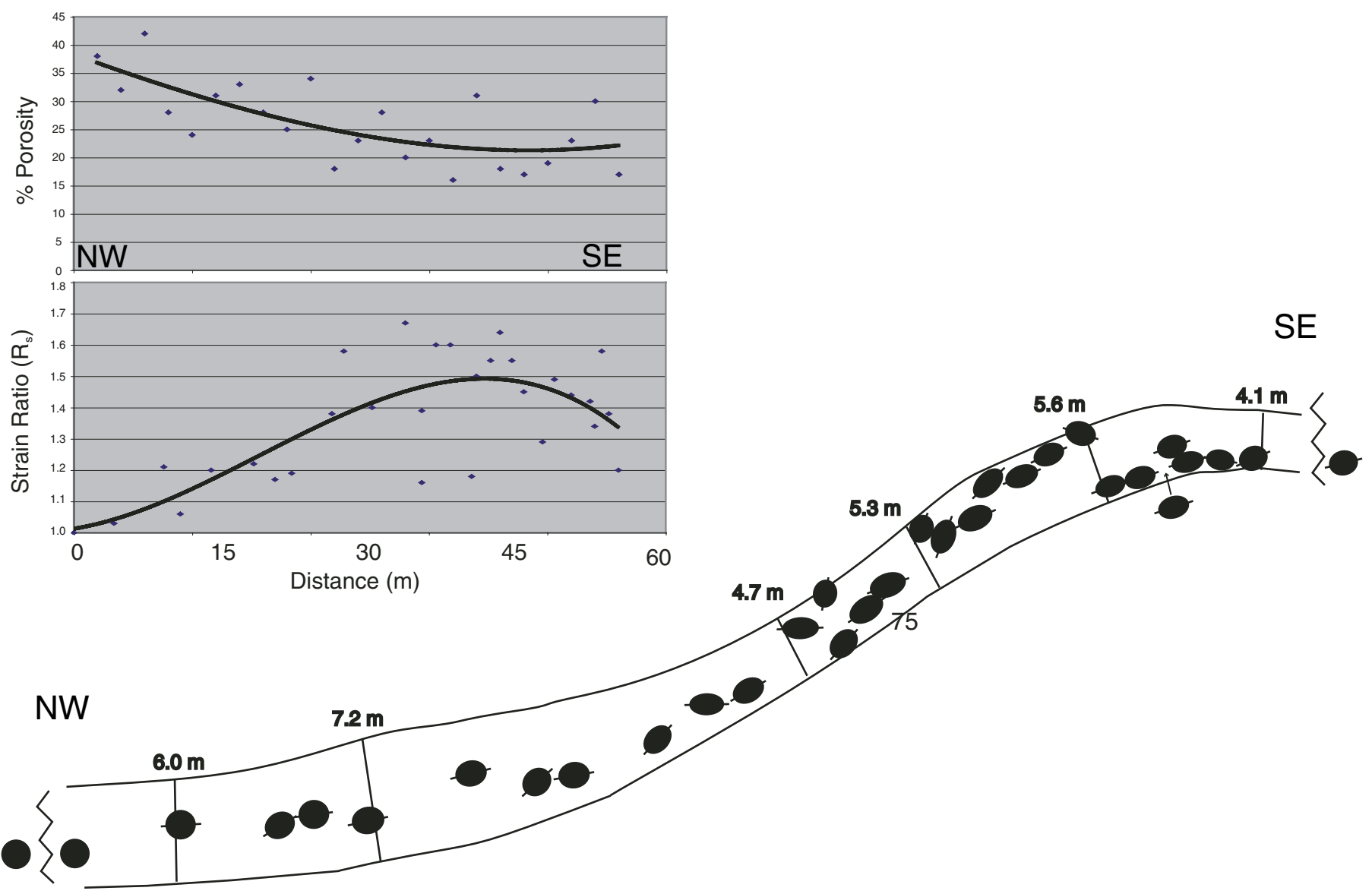

Figure 14. Changes in thickness, strain, and porosity along the massive red sandstone bed as it rises up over the margin of the Trachyte Mesa laccolith.

subvertical outward margin of the growing/stacking laccolith. The thinner bedded sandstones and shales immediately at the contact are more readily deformed and conform to the outermost shape of the contact. Because the magma is under high pressure, the decrease in pressure at these voids is immediately filled by tongue-like sheets, which at this time originate from the exterior margin of the accumulating stack. In our model, these tongue-like sheets were emplaced solely as a result of this low-pressure zone. This implies that changes in magma pressure are communicated throughout the growing body, even though the body as a whole is constructed of individual sheets. This idea of magma pressure communication is supported by the observation that all the tongue-like sheets at the base arrested at the same outward distance from the Trachyte Mesa laccolith, even through they were midway through deforming upturned sandstone layers. Once these tongues filled the low-pressure zone, it once again becomes more favorable to create sheets on top or elsewhere. Therefore in our model, the location and type of sheet is partly controlled by the strength, position, and orientation of the wall rocks, which are continually changing as more sheets are emplaced. The accumulation of sheets results in a flat-topped laccolith, which is actually the most common shape for the top of a laccolith (Corry, 1988).

\section{Directions to Stop 2.2}

From the edge of the mesa here, walk toward $150^{\circ}$ for $200 \mathrm{~m}$ until you see an $\sim 1$-m-thick sandstone bed eroding into blocks on top of the laccolith.

\section{Stop 2.2: Sandstone Roof of the Trachyte Mesa Laccolith}

Main points: (1) The current exposure of the top of the Trachyte Mesa laccolith is at or very close to the actual upper contact. (2) The same 1 -m-thick sandstone bed can be found at the upper contact on the SE, top, and NW margins, and bits and pieces of it can also be found throughout the top in the NE half of the mesa.

This sandstone bed here resembles the sandstone observed at Stop 1.10, Stop 1.12, and Stop 2.1a and is lying at the contact with the igneous rock of the Trachyte Mesa laccolith below. 
A

$A^{\prime}$

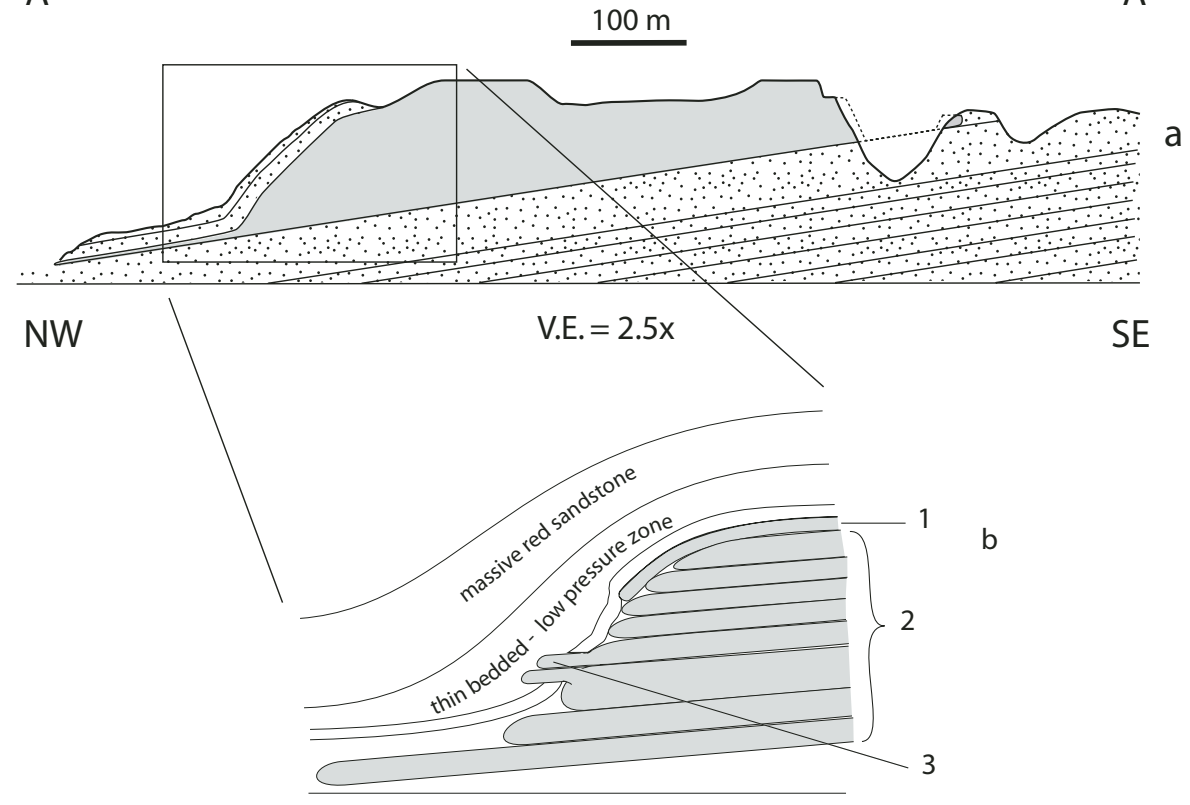

Figure 15. Cross sections through Trachyte Mesa laccolith. See Figure 9 for location of the section. Numbers on the lower, detailed section of the NW margin refer to the relative timing of emplacement of sheets.

\section{Directions to Stop 2.3}

Walk $100 \mathrm{~m}$ WSW to small knob of igneous rock. Looking NE there is an overlook of the SW half of the Trachyte Mesa laccolith and looking SW there is a plateau of alluvium that extends to the SW.

Stop 2.3: Overview of Internal Fabric, Geophysical Evidence for Hidden Conduits and Final Emplacement of the Trachyte Mesa Laccolith

GPS (UTM): 536132, 4199471. Main points: (1) Magmatic fabric characterizes most of the intrusion. (2) The Trachyte Mesa laccolith can be divided into two zones based on orientation of magnetic lineations. The dominant orientation is to the NE, parallel to the long axis of the intrusion, and is found mainly in a linear zone running down the axis of the intrusion. (3) Magnetic anomaly data supports a NE-oriented pipe-like body at depth under the alluvium to the SW. This body is along a line extending from Mount Hillers toward Trachyte Mesa laccolith and possibly supplied magma to the intrusion. (4) Parallelism between the orientation of the (a) magnetic anomaly, (b) magnetic lineations, (c) orientation of the long axis of the intrusion, and a line that passes between Mount Hillers and the Trachyte Mesa laccolith strongly suggests that Mount Hillers is the feeder that supplied magma to the Trachyte Mesa laccolith.

This is a good vantage point to discuss the fabric of the Trachyte Mesa laccolith and the AMS pattern collected from on top of the intrusion. Microstructures from the surface of this outcrop support the interpretation of a magmatic (versus solid state) fabric. Phenocrysts of undeformed, euhedral plagioclase are mostly not in contact with other crystals. The lineation, which is much stronger than the foliation $(\mathrm{L}>\mathrm{S})$, is defined by elongate hornblende phenocrysts. In sections perpendicular to both foliation and lineation, it is often difficult to define the foliation.

The AMS (magnetic) lineations from the top of the Trachyte Mesa laccolith are very shallowly plunging and vary in orientation from SE to NE with the strongest concentration to the NE (Fig. 16). Magnetic foliations are subhorizontal. Based on patterns, we have divided the lineations from the Trachyte Mesa laccolith into two domains. The NE half of the intrusion contains a central linear zone where the lineations are consistently parallel to the long axis of the intrusion (trending NE). Away from this central zone, lineations fan and diverge outward to the NNW and ESE. In the SW half of the intrusion, the pattern of lineations is more complex but seems to define a central zone that curves but is approximately E-W. South of this belt, the lineations fan outward to the S. Figure 16 also shows possible flow paths based on the magnetic lineations. The significance of these paths will be discussed later.

Magnetic anomaly data was collected along three traverses over part of the alluvial plateau to the SW of the Trachyte Mesa laccolith (Fig. 17). Although the data is limited, all three traverses indicate that there is at least one large anomaly at depth that can be traced from the SW to the NE, toward the Trachyte Mesa laccolith. The anomaly peak decreases in width and increases in intensity to the NE, suggesting that the higher susceptibility material causing the anomaly is shallowing toward the NE, toward the Trachyte Mesa laccolith. A line that connects the anomalies from the three traverses (Fig. 17) broadly intersects the Trachyte Mesa laccolith in the location that the magnetic lineation pattern emanates from (Figs. 9 and 16). Nugent et al., 


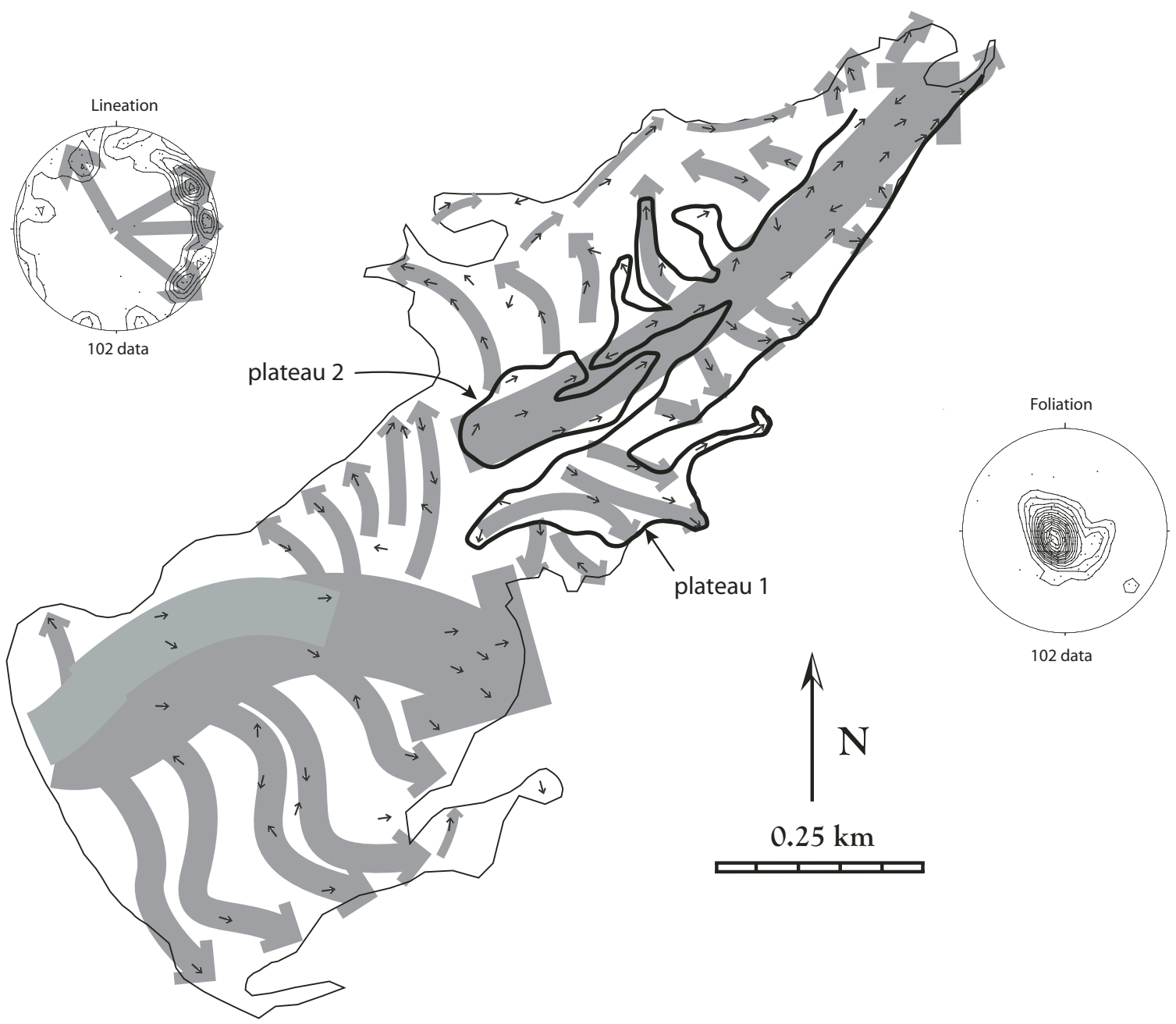

Figure 16. Magnetic lineations on top of Trachyte Mesa laccolith. Shaded arrows are interpreted flow paths of magma from the uppermost sheets

(2003) modeled the magnetic anomaly data (in two dimensions, using GM-SYS software) and found that they could not replicate the anomalies using dikes cutting up through sandstone. Nugent et al. (2003) were able to reproduce similar anomaly patterns using polygonal shapes of low aspect ratios at a depth of $\sim 40 \mathrm{ft}$.

There is a small outcrop of diorite porphyry located approximately halfway between Mount Hillers and the Trachyte Mesa laccolith, described (with cross sections) by Hunt (1953). The igneous body is linear in shape and aligned along a line connecting Mount Hillers to the Trachyte Mesa laccolith. One lateral margin of this body is exposed along a 2-m-high cliff with an irregular step-like contact. The actual base of the intrusion is not exposed. The other side of this body, where exposed, is very irregular in shape. The top is flat. The elevation of this body is much higher than the elevation of the Trachyte Mesa laccolith, but the position between Mount Hillers and the satellite Trachyte Mesa laccolith, as well as its alignment suggests a connection between Mount Hillers and the laccolith.
The magnetic lineation map from the top of the Trachyte Mesa laccolith (Fig. 16) suggests that the magma from the top sheets flowed along the long axis of the intrusion and spread radially outward to both sides. This pattern is particularly apparent in the NE half of the intrusion. In the SW half, the pattern of magma flow is more complex. We suggest this radial pattern is consistent with a linear centralized source that feeds sheets or fingers to both sides, but originates from the $\mathrm{SW}$ and is flowing generally to the NE. The magnetic lineations are also subparallel to the long axis of the plateaus in the NE half of the intrusion (Fig. 16) and support the hypothesis that the plateaus represent sill-like sheets.

The map (Fig. 9) of the Trachyte Mesa laccolith illustrates that finger-like shapes protrude outward from the main body parallel to the long axis and also perpendicular to it, similar to what is observed at the Maiden Creek sill and consistent with the flow pattern obtained from the AMS lineations. We do not believe that these fingers are merely erosional remnants because 
(a) the thicknesses of some are at a very different level than the main intrusion, and (b) some of their lateral margins bulge, similar to the true terminal margins (where wall rocks are exposed on the margins) of sheets observed elsewhere. The NE tip of the Trachyte Mesa laccolith is also shaped into two small "pinchers," similar to how fingers seem to "pinch" at the NE margin of the Maiden Creek sill (Fig. 4).

The dominant lineation orientation is along a line that can be traced directly back to Mount Hillers, $12 \mathrm{~km}$ away, which is also parallel to the long axis of the intrusion. The magnetic anomaly data is consistent with a magma tube (finger?) originating from Mount Hillers, which intersects the Trachyte Mesa laccolith at the location the magnetic lineations emanate from. Dikes are rare in the Henry Mountains, and dikes have not been observed anywhere near these satellite intrusions. We do not understand why magma coalesced to produce an intrusion at this location, but the data does support a model whereby intrusions are fed by magma fingers. The Trachyte Mesa laccolith may have originated as one long finger that began to branch outward into smaller fingers. Fingers expand their margins and coalesce with other fingers, which may be what we are observing at the NE margin of the Trachyte Mesa laccolith and Maiden Creek sill, where two fingers crystallized before completely coalescing. Fingers therefore evolve into sheets that are $\mathrm{m}$-scale in thickness. Once a sheet is constructed, more sheets follow, but their sequence into the stack of sheets is not orderly, and partly based on wall-rock geometry and deformation.

\section{Part II: Sawtooth Ridge Intrusion and Black Mesa Bysmalith}

\section{Directions to Stop 2.4}

Walk SSE back to the cars and drive back NE down the dirt road until intersection with Utah Hwy 276. Turn right (S) and set odometer to zero. We are returning to the same location where we parked yesterday when we examined the Maiden Creek intrusion (see directions for Stop 1.2). Figure 18 shows the location of the stops on the Sawtooth Ridge and Black Mesa intrusions. After parking the car, walk uphill toward $225^{\circ}$ (SW) for $\sim 400 \mathrm{~m}$. Once a reasonably flat plateau is reached, the tallest knob provides a good view of the Sawtooth Ridge and Black Mesa intrusions.

\section{Stop 2.4: Sawtooth Ridge Intrusion and Black Mesa Bysmalith Overview}

GPS (UTM): 535387, 4195607. Main points: (1) Sawtooth intrusion exhibits evidence for multiple intrusive sheets with bulbous terminations. (2) Black Mesa is a bysmalith (faultbounded intrusion) with flat-lying sediments on top. (3) There are weathering differences between the top $\sim 40 \mathrm{~m}$ of the Black Mesa bysmalith and the main part of intrusion ( $200 \mathrm{~m})$. We suggest these differences may reflect the sheeted nature of the top. (4) The magma conduit to the Black Mesa bysmalith must be from bottom of the intrusion in order to raise the sedimentary "roof" rocks.

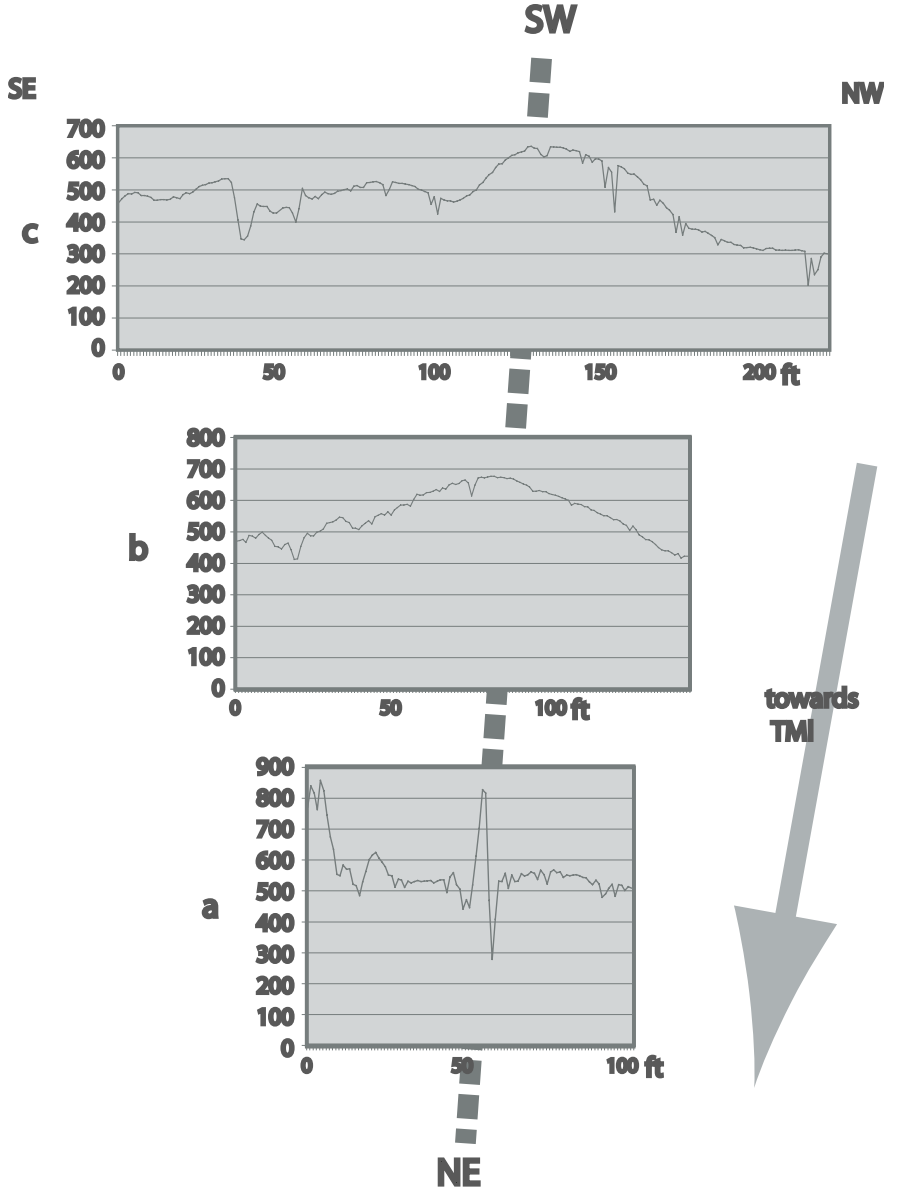

Figure 17. Magnetic intensity (+52,000 gammas) collected along three traverses over plateau SW of the Trachyte Mesa laccolith (TMl). See Figure 9 for location of traverses.

Look WSW at the cliff face and a cross section view of the Sawtooth Ridge intrusion (Fig. 19). The Sawtooth Ridge intrusion is a highly elongate, narrow body with a jagged top from which the intrusion gets it name. The elongate direction of Sawtooth Ridge points radially away from the central part of the Mount Hillers intrusive center. The cliff face exposes the complex shape of this intrusion (Fig. 19). From this vantage point, the general direction of magma flow during emplacement of this portion of the Sawtooth Ridge was presumably ENE, or out of the cliff and toward the viewer (assuming the magma flowed parallel to the long axis of the intrusion). Bedding in the sedimentary wall rocks is bent and faulted over the top of the intrusion. Two $\sim 5 \mathrm{~m}$ thick sheets, each of which ends in a bulbous termination, are clearly visible extending out from a more massive central body. We interpret these lateral "extensions" as separate sheets, based on our observations of other satellite intrusions in the region. This is our only examination of the Sawtooth Ridge intrusion.

Looking WNW, the Black Mesa bysmalith is a cylindrical pluton $1.7 \mathrm{~km}$ in diameter and roughly $250 \mathrm{~m}$ thick (Fig. 20). 

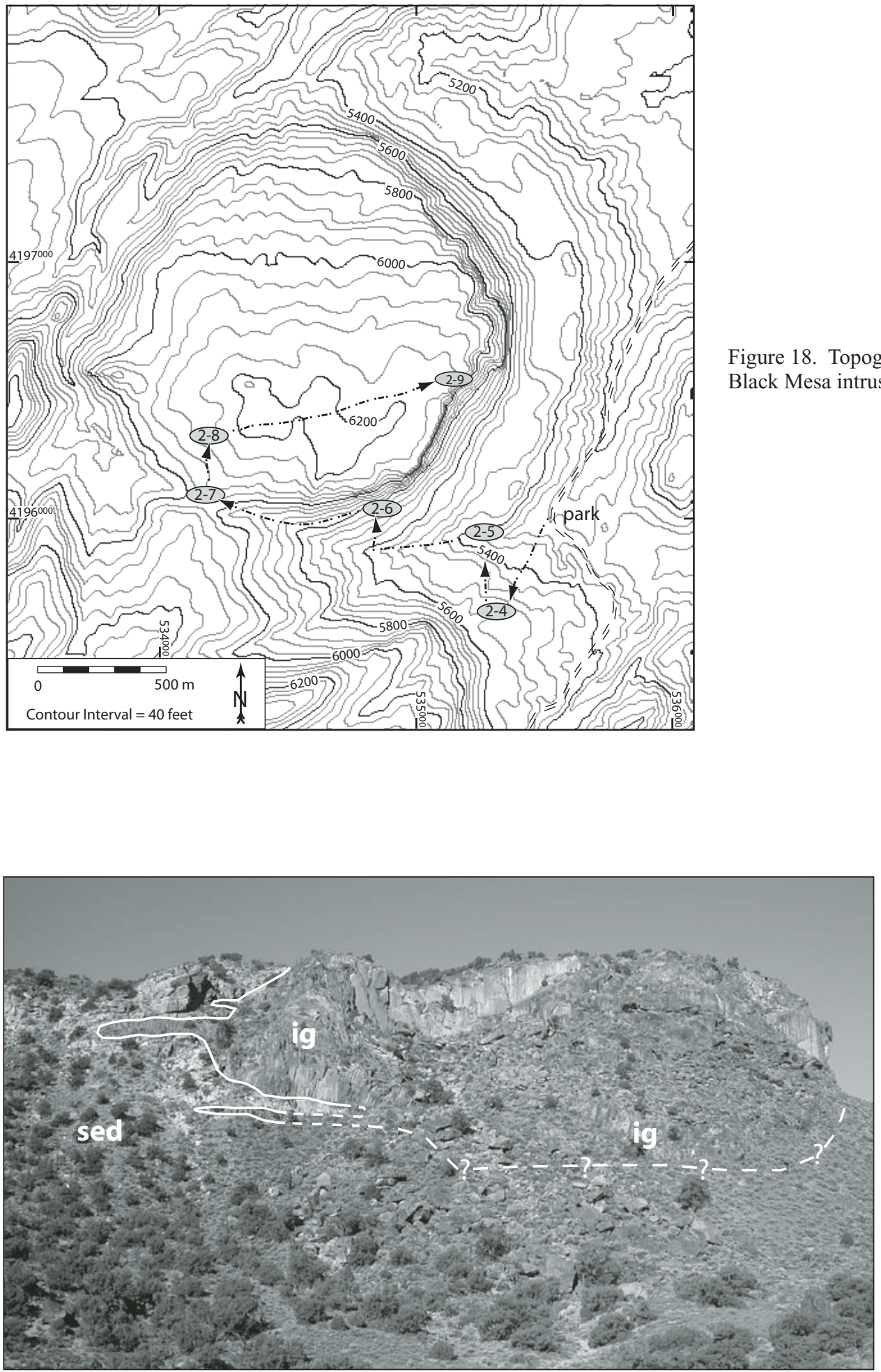

Figure 18. Topographic map of the Sawtooth Ridge and Black Mesa intrusions with stops indicated.
Figure 19. Photo of Sawtooth Ridge intrusion taken from Stop 2.4. Cliff is $\sim 30 \mathrm{~m}$ high. ig-igneous; sed-sedimentary. 
Differential erosion between the surrounding sedimentary rocks and the igneous rocks has produced a very distinct mesa that outlines the intrusion (Fig. 21). Technically, the Black Mesa bysmalith is transitional between two forms of intrusions. The E side, which you are looking at, is a bysmalith: a piston-like, cylindrical intrusion that accommodated upward wall rock displacement mainly through faulting. Bysmaliths typically have flat roofs that are sharply truncated by vertical, curved faults (Figs. 20 and 21). The western portion of Black Mesa bysmalith is a laccolith, as the wall rocks are folded into a syncline but not faulted (Fig. 22).

From this vantage point, one can observe two different erosional patterns on the lateral margin of the Black Mesa bysmalith. The top $(\sim 40 \mathrm{~m})$ of the intrusion has a layered look, while the remainder of the pluton looks massive. As we will discuss at Stop 2.7, these differences in weathering coincide with distinctive patterns of AMS lineations.

\section{Directions to Stop 2.5}

Walk downhill $\sim 300 \mathrm{~m}$ toward $355^{\circ}$ and into the stream valley that runs E-W on the SE side of Black Mesa. Stop in the stream valley.

\section{Stop 2.5: Bottom of Black Mesa Bysmalith}

Main point: (1) Sedimentary rocks below intrusion are undeformed.

The Black Mesa bysmalith is surrounded by subhorizontal strata, which abruptly change orientation and become subvertical at the contact. The roof of the bysmalith is flat, slightly N-dipping, and covered by concordant sedimentary strata of the Morrison formation. The presence of this formation at the base and the top of the intrusion in a flat lying geometry led Hunt (1953) and

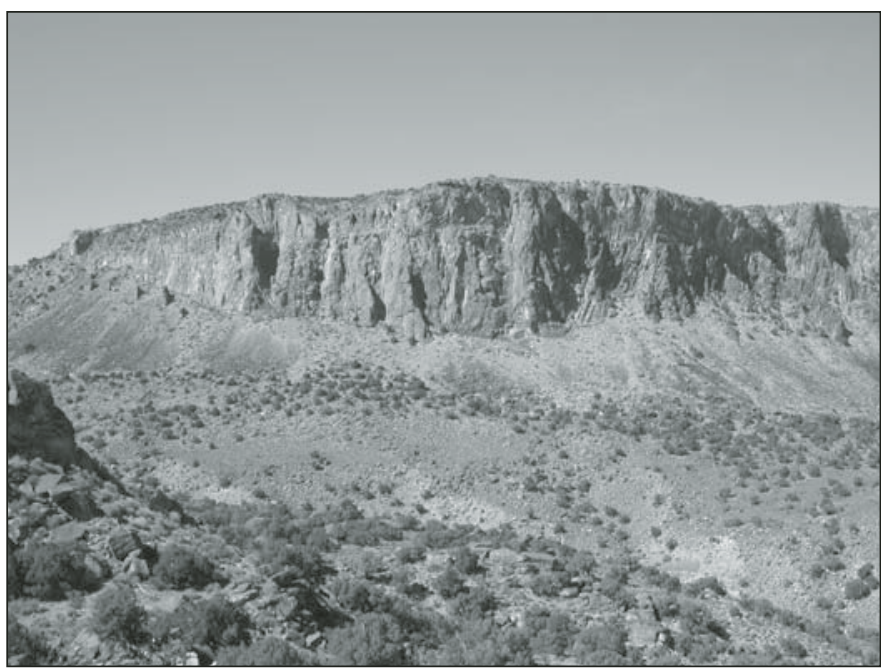

Figure 20. Photo of SSE margin of Black Mesa bysmalith taken from Stop 2.4. Cliff is $\sim 130 \mathrm{~m}$ high.

Jackson and Pollard (1988) to conclude that the floor of the intrusion is close to the current bottom exposure. Based on the stratigraphic section compiled by Jackson and Pollard (1988), who estimated thicknesses through regional correlation, a maximum of $2.5 \mathrm{~km}$ of sedimentary rocks overlay the Morrison formation at the time of emplacement, which constitutes the lithostatic load over the roof of Black Mesa bysmalith.

At this stop, we will examine the sedimentary strata of the Morrison formation immediately below the intrusion. The rocks here are essentially undeformed and unmetamorphosed.
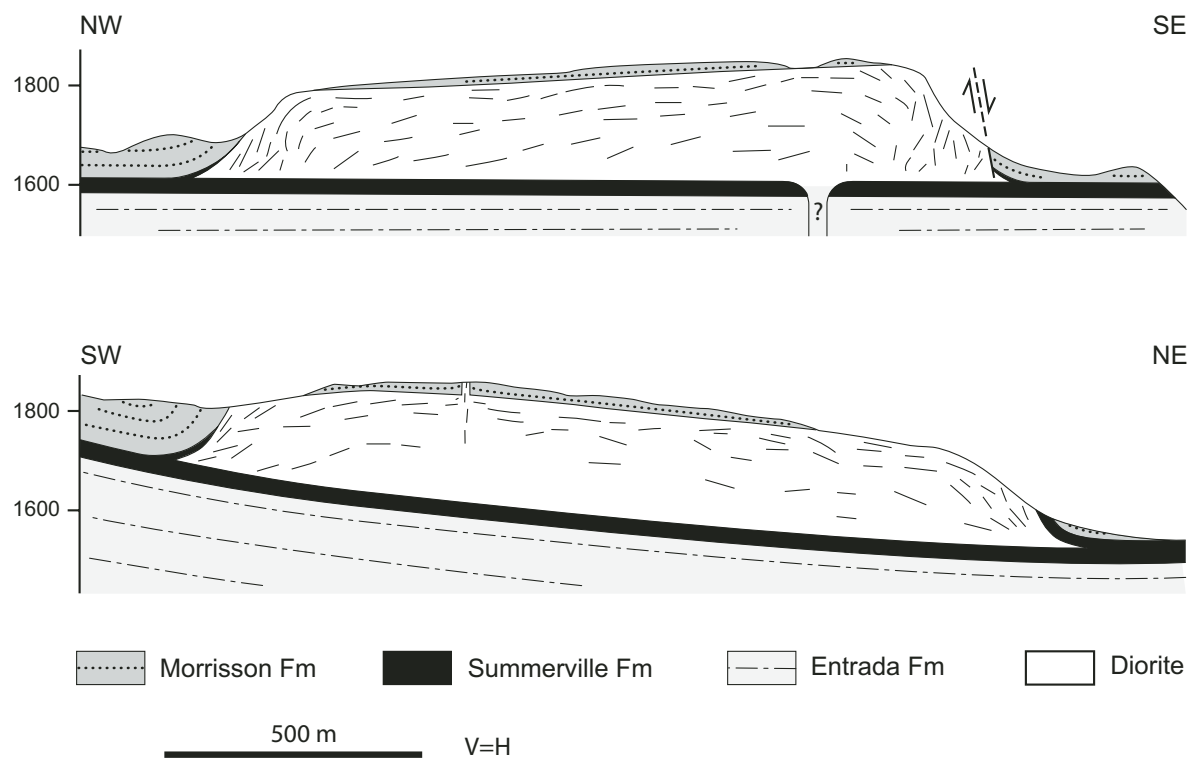

Figure 21. Cross section through Black Mesa bysmalith. 


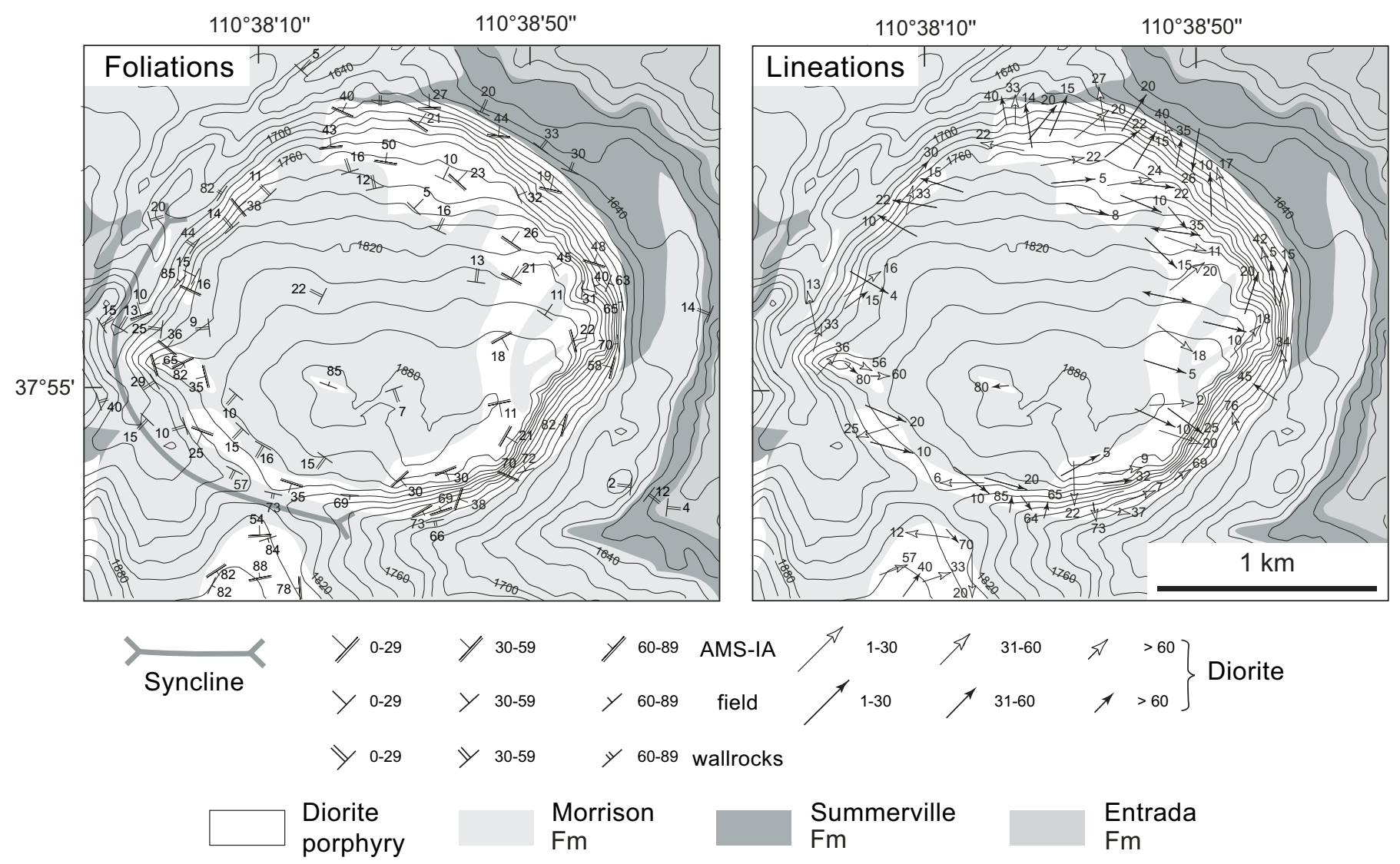

Figure 22. Map of Black Mesa bysmalith showing foliations and lineations. AMS-IA—anisotropy of magnetic susceptibility assisted by image analysis.

\section{Directions to Stop 2.6}

Follow the stream valley uphill and to the $\mathrm{W}$ for $\sim 0.5 \mathrm{~km}$. Walk due $\mathrm{N}$ out of the stream bed and uphill for $\sim 200 \mathrm{~m}$ toward the cliff that delineates the southern margin of the Black Mesa bysmalith.

\section{Stop 2.6: Cataclastic Bands on the Margin of the Black Mesa Bysmalith}

Main point: (1) Subhorizontal cataclastic bands on the margin of the Black Mesa bysmalith are similar to those observed at the Trachyte Mesa laccolith, where they delineate separate magma sheets.

On the cliff face of the Black Mesa bysmalith here, there are 1-2-m-thick subhorizontal zones rich in anastomozing cataclastic bands separated by $10-20 \mathrm{~m}$ of undeformed igneous rock (Habert and de Saint Blanquat, 2004). On the margins of the Trachyte Mesa laccolith, sheets are partly identified by similar zonation of brittle deformation and no deformation. Although, sheets are also delineated at the Trachyte Mesa laccolith by $2-3-\mathrm{cm}$-thick shear zones at the contacts, and this is not observed here.

\section{Directions to Stop 2.7}

Walk $\mathrm{W} \sim 0.5 \mathrm{~km}$, contouring around the cliff and up to the saddle on the SSE margin of the Black Mesa bysmalith.

\section{Stop 2.7: Black Mesa Bysmalith in the Saddle}

Main points: (1) Composition and fabric of the Black Mesa bysmalith is very similar to the Maiden Creek sill and the Trachyte Mesa laccolith. (2) Complex relation (more intrusions) with main Mount Hillers body. (3) AMS lineation data indicates shallow plunges on top and moderate to steep plunges on side, which corresponds to geomorphic distinction between top and bottom of intrusion.

A typical specimen of the Black Mesa bysmalith is very similar to the Maiden Creek sill or the Trachyte Mesa laccolith. It is a diorite porphyry with a microgranular porphyritic texture and consists of $\sim 50 \%$ phenocrysts (oligoclase $30 \%$, hornblende $10 \%$, augite $5 \%$, magnetite and titanite $<5 \%$, apatite $<1 \%$ ) and $~ 50 \%$ groundmass (mostly plagioclase and hornblende).

The magmatic fabric at Black Mesa bysmalith is ubiquitous and is defined by the preferred orientation of plagioclase and hornblende phenocrysts. The lineation is strong but the foliation is 
sometimes difficult to recognize in the field, similar to the Maiden Creek sill and the Trachyte Mesa laccolith. Fabric orientation varies with vertical position in the body. Subhorizontal foliations occur at the top and the bottom of the intrusion, and steeper, inward-dipping foliations occur in the middle of the intrusion. The preferred orientation of hornblende is the more obvious field structure and defines an easily measurable lineation.

Ductile and/or cataclastic deformation is observed in a few locations near the top of the pluton-wall rock contact, where the first few centimeters of the intrusion are sheared. Along the margins at vertical contacts, undeformed hornblende phenocrysts are aligned parallel to vertical fault striations, suggesting that fault movement was synmagmatic. Shear sense indicators show that magma moved upward relative to wall rocks during the emplacement, which is in agreement with the tilting of the surrounding wall rocks.

This fabric is characterized, on the scale of the intrusion, through the use of AMS. The magnetic foliations on the surface of the pluton (Figs. 21 and 22) define an outward dipping domeshaped pattern, which is concordant with the pluton's margins. Thus, the pluton margin exerted a strong influence on flow and/or deformation within the interior of the evolving pluton. Steep foliations, that are sometimes inward dipping, are found along the eastern margin of the pluton and could be related to vertical flow due to peripheral fault activity.

The magnetic lineations are much more instructive. Magnetic lineations within the pluton are characterized by a trimodal distribution of trends and dip (Fig. 22; also see Habert et al., 2005): (1) lineations localized on the very top of the intrusion have a general WNW-ESE trend; (2) lineations from sites below the roof of the Black Mesa bysmalith have a NNE-SSW trend; and (3) lineations localized along the eastern margin and within late dikes are vertical. Lineations are generally subhorizontal, except along the eastern margin where subvertical lineations were measured, and also in WNW-striking vertical dikes, which cut the pluton's roof. These patterns support the inference, based on morphology, that the top of the pluton was intruded in a different manner than the lower, massive part of the intrusion.

Located at the SSW end of the Black Mesa bysmalith, and in apparent morphological continuity with it, is a diorite ridge or saddle (Figs. 18 and 22). Hunt (1953) suggested this was a lateral injection zone that supplied the intrusion with magma. Our data does not support this interpretation. First, detailed mapping indicates that these two bodies are separated by the host rock of the Morrison Formation, a result that is supported by a SW-NE gravity profile (G. Habert, personal commun., 2003). Second, the two bodies have different phenocryst contents and are of slightly different petrographic facies. Last, the presence of a lateral feeder zone should have induced a symmetry in the internal fabric pointing toward the feeder, presumably toward the SSW, which is not observed in the AMS patterns (e.g., the lineation pattern is not radial from where the diorite body would connect to the body).

Our observation of an axial symmetry of the fabric pattern supports a model where magma is injected from a conduit situ- ated below the Black Mesa bysmalith, in an approximately axial position. This is consistent with an earlier suggestion by Pollard and Johnson (1973) for a vertical feeder dyke below the bysmalith. The exact nature, geometry, and orientation of this feeder are not possible to determine precisely with our data. There are, however, the two planes of symmetry of the fabric (NNE-SSW or WNW-ESE) that may provide some constraints on the orientation of the feeder zone.

\section{Directions to Stop 2.8}

Walk $\sim 200 \mathrm{~m} \mathrm{~N}$ to any of several outcrops of Morrison Formation sandstone.

\section{Stop 2.8: Flat-Lying Sedimentary Rocks on Top of the Black Mesa Bysmalith}

Main point: (1) Flat-lying sedimentary rocks of the Morrison Formation on the top of the Black Mesa bysmalith require an upward translation of $\sim 250 \mathrm{~m}$ without rotation or distortion.

The roof of the Black Mesa bysmalith is flat, slightly N-dipping, and covered by concordant sedimentary strata of the lower part of the Morrison formation. These strata are equivalent to the flat lying, unmetamorphosed strata surrounding the base of the intrusion. This geometry requires that these wall rocks were translated vertically by $\sim 250 \mathrm{~m}$, without any rigid-body rotation or internal distortion.

The asymmetric form of the intrusion, with its gently N-dipping roof (Figs. 21 and 22) is associated with a thickness increase toward the E, and can be attributed to the combination of (1) a primary asymmetry developed during emplacement, with more magma injected at the eastern part of the pluton, and (2) a tilt toward the NE due to the growth of Mount Hillers.

Although it is difficult to observe at this location on the top of the intrusion, the fabric of the intrusion immediately below the roof rocks typically shows a pattern similar to that observed in both the Maiden Creek and Trachyte Mesa intrusions. On the western margin, a very clear stretching lineation trending $310^{\circ}$ is measurable in the field, immediately underneath the contact, which is different from the $010^{\circ}$ measurement obtained by AMS on a sample taken $20 \mathrm{~cm}$ below this contact. Given that the lineation below this layer differs for the remainder of the intrusion, we hypothesize that the topmost part of the intrusion was intruded first, probably as a sill.

\section{Directions to Stop 2.9}

Walk toward 080 (ENE) for $\sim 1 \mathrm{~km}$. Please stop when you reach a precipitous drop-off.

\section{Stop 2.9: Overview and Emplacement of the Black Mesa Bysmalith}

Main points: (1) Comparison of evidence for sheeting in the Black Mesa bysmalith with the Maiden Creek sill and the Trachyte Mesa laccolith. (2) Emplacement model for the Black Mesa bysmalith.

This location provides an overview of the three principal bodies that we have investigated on this field trip: The Maiden 
Creek sill, the Trachyte Mesa laccolith, and the Black Mesa bysmalith. We envision that each of these bodies represents a temporal succession of the three stages of pluton assembly: (1) sill intrusion, (2) inflation through stacking of sheets and accommodated by overburden bending, and (3) inflation accommodated by roof lifting along peripheral faults. The Maiden Creek sill records evidence only of the first episode, the Trachyte Mesa laccolith records the first two stages, and the Black Mesa bysmalith records evidence for all three. The clear recognition of individual magma injections may be lost in the third stage. We hypothesize, however, that this mechanism may continue to function during the later stages of emplacement.

Given that the emplacement history of Maiden Creek sill and the Trachyte Mesa laccolith were covered earlier, we focus primarily on Black Mesa bysmalith. In summary, the sill-like part of the evolution of the intrusion is characterized by the WNWESE cataclastic lineations on the top of the pluton, and also the cataclastic banding we saw at Stop 2.6. These early cataclastic fabrics are also the key to the underlying magmatic fabrics. First, there is a very sharp transition from cataclastic microstructure within the first centimeters of the upper contact to the magmatic texture below. Second, this transition correlates with a change in lineation orientation from WNW-ESE at the contact to NNESSW below the contact. This latter effect was not observed in the Maiden Creek sill or the Trachyte Mesa laccolith.

We present two possible models to explain the change in lineation orientation from the top to the rest of the intrusion. In both models, the lineation records the first relative movement between the magma and the wall rocks during the formation of a sill between the bottom of the Morrison Formation and the top of the Summerville Formation. In the first model, the pattern of cataclastic lineations indicates that the sill fabric was controlled by the orientation of the magma source. If we assume that the cataclastic microstructures directly record magma flow (WNW), then the underlying lineations reflect a stretching perpendicular to and away from a NNE-oriented dike. Thus, the original feeder may have been a dike (Pollard and Johnson, 1973) oriented vertically and NNE-SSW. Due to the strong temperature contrast between magma and host rocks at that time, the external part of the first pulse was chilled and cataclastically deformed during magma injection. In contrast, later magmatic fabrics within the evolving sill are controlled by the orientation of the sill plane, i.e., parallel to the gently NNE-dipping sediments, and therefore magma flowed NNE-SSW along this plane. We interpret the fabric to record strain, specifically stretching due to pluton inflation.

In the second model, the lineations record motion away from a central, subhorizontal feeder, similar to the lineation pattern from the sheets on top of the Trachyte Mesa laccolith, which we suggest reflect outward, radial growth from a central, NNE-oriented zone. Here at Black Mesa bysmalith, the centralized NNE zone is covered by the sedimentary rocks on the top and we only see the margins where radial spreading is exposed.

Except for the first few centimeters to meters, the only major internal fabric changes between the upper part of the pluton (the initial sill) and the igneous mass below are the zones of anastomosing cataclastic bands separating 10-20-m-thick layers of undeformed diorite observed at Stop 2.6. The similarity between these and the zones of cataclastic bands that define sheets in the Trachyte Mesa laccolith suggest that the Black Mesa bysmalith was constructed from a series of sheets. The lack of a well-defined shear zone at the boundary between sheets, like those observed at the Trachyte Mesa laccolith, suggests that the thermal regime was different between the two intrusions (see Habert and de Saint Blanquat, 2004). It should be noted that the internal portions of the Trachyte Mesa laccolith also do not preserve internal contacts (Stop 1.11). It may be that the sheeting mechanism is only viable at the outermost contacts, or that sheeting within the hotter interiors does not result in solid-state deformation.

In the sheeting growth model, the final size of the laccolith is partially controlled by the area of the initial sill. Upward bending of wall rocks occurs only at the tip of the intruding pulse. The marginal wall rocks are dominantly translated with only minor thinning because of the small area increase associated with upward growth and stretching around the intrusion. The parallelism between magmatic and solid-state lineations in the wall rocks suggests that the fabric formed during emplacement and is not late.

Our proposed kinematic model is that each pulse of magma intruded subhorizontally. We do not know if later sheets intrude below or above the previous one, but based on the observations on top of the Trachyte Mesa laccolith, we assume that during the laccolith stage younger sheets are sometimes emplaced on top of older sheets.

We hypothesize that the transition from Trachyte Mesa laccolith-style intrusion to the Black Mesa bysmalith-style may occur when enough sheets have accumulated so that the marginal wall rocks have been rotated to nearly vertical. At this point in the evolution of the magma chamber, faulting becomes a viable mechanism to accommodate vertical growth, partly because of the increase in area that the marginal wall rocks are subjected to during vertical accretion, and partly because the wall rocks have rotated to their maximum amount (vertical) and no further vertical growth can be accommodated by further rotation. At this point in the evolution of the intrusion, there is little evidence that sheeting continued to be the emplacement mechanism. Further, the vertical offset of the Morrison Formation to become the "roof," indicates that the Black Mesa bysmalith was fed, at least during the major growth stage, from below.

The Black Mesa bysmalith is a complex intrusion in that the margins are not similar all along the pluton's periphery. We suggest that at least part of the laccolith stage may be preserved on the western margin. The margin along the eastern half is marked by peripheral faults, which have accommodated most of the roof lifting, whereas the margin along the western half is marked by a syncline whereby wall rocks are contiguous from the surrounding area up to the top of the intrusion. This intrusion is therefore more complex than previously described by Hunt (1953) and Pollard and Johnson (1973), and a simple plug model is not appropriate. 
In summary, the Black Mesa bysmalith appears to have gone through a sill phase, a laccolith phase, and then a finally a bysmalith phase along its eastern margin. There is evidence for the first two phases within the Black Mesa bysmalith, but there is no definitive evidence for sheeting during the final bysmalith phase. However, the relatively large volume of magma present during inflation of Black Mesa bysmalith would cool relatively slowly and be unlikely to preserve evidence of contacts between sheets (Habert and de Saint Blanquat, 2004).

These satellite intrusions only occur on the ENE side of Mount Hillers (Fig. 1). On the E, SE, and S sides of Mount Hillers, there are no satellite intrusions but the sedimentary section on the margins of Mount Hillers is rotated to steep dips (Jackson and Pollard, 1988). On the ENE side of Mount Hillers, sedimentary rocks with shallow to moderate dips can be traced high up the mountainside. The transition between these two regions of different dips occurs at the Sawtooth Ridge. We suggest that the Sawtooth Ridge intrusion may be emplaced along a scissor-fault that accommodated the differences in dips between the two regions. We also speculate that the reason that there are no satellite intrusions on the $\mathrm{S}$ side of Mount Hillers is because the strata were already rotated to steep dips, and therefore magma pushing outward was unable to pass easily through the steep "wall" of upturned strata, whereas on the ENE side of Mount Hillers, magma was able to flow outward along bedding planes to feed the satellite intrusions. This model assumes that the satellite intrusions were fed by sills or magma fingers, which is supported by the magnetic anomaly data SW of the Trachyte Mesa laccolith. This model also assumes that the Mount Hillers intrusive center was emplaced earlier than the satellite intrusions.

\section{End of Trip}

Retrace your steps. Head back north and east on the dirt road until the intersection with Utah Hwy 276. Turn left and drive north on Hwy 276, then turn left on Hwy 95 and drive north to Hanksville.

\section{REFERENCES CITED}

Cañón-Tapia, E., and Coe, R., 2002, Rock magnetic evidence of inflation of a flood basalt lava flow: Bulletin of Volcanology, v. 64, p. 289-302, doi: 10.1007/s00445-002-0203-8.

Corry, C.E., 1988, Laccoliths; Mechanics of emplacement and growth: Geological Society of America Special Paper 220, 110 p.
Engel, C.G., 1959, Igneous rocks and constituent hornblendes of the Henry Mountains Utah: Geological Society of America Bulletin, v. 70, p. 951-980.

Fillmore, R., 2000, The parks, monuments, and wildlands of southern Utah: a geologic history with road logs of highways and major backroads: Salt Lake City, University of Utah Press, 268 p.

Gilbert, G.K., 1877, Report on the geology of the Henry Mountains: U.S. Geographical and Geological Survey, Rocky Mountains Region, 160 p.

Habert, G., and de Saint Blanquat, M., 2004, Rate of construction of the Black Mesa bysmalith, Henry Mountains, Utah, in Breitkreuz, C. and Petford, N., eds., Physical Geology of High-Level Magmatic Systems: Geological Society [London] Special Publication 234, p. 163-173.

Habert, G., de Saint Blanquat, M., Horsman, E., Morgan, S., and Tikoff, B., 2005, Mechanisms and rates of non-tectonically assisted magma emplacement in the upper crust: The Black Mesa bysmalith, Henry Mountains, Utah: Tectonophysics (in press).

Horsman, E., Tikoff, B., and Morgan, S.S., 2005, Emplacement-related fabric in a sill and multiple sheets in the Maiden Creek sill, Henry Mountains, Utah: Journal of Structural Geology (in press).

Hunt, C.B., 1953, Geology and geography of the Henry Mountains region, Utah: U.S. Geological Survey Professional Paper 228, 234 p.

Hunt, C.B., 1988, Geology of the Henry Mountains, Utah, as recorded in the notebooks of G.K. Gilbert, 1875-76: Geological Society of America Memoir 167, 229 p.

Jackson, M.D., and Pollard, D.D., 1988, The laccolith-stock controversy: New results from the southern Henry Mountains, Utah: Geological Society of America Bulletin, v. 100, p. 117-139, doi: 10.1130/00167606(1988) $100<0117$ :TLSCNR>2.3.CO;2.

Johnson, A.M., and Pollard, D.D., 1973, Mechanics of growth of some laccolithic intrusions in the Henry Mountains, Utah: I: Tectonophysics, v. 18, p. 261-309, doi: 10.1016/0040-1951(73)90050-4

Kelsey, M.R., 1990, Hiking and exploring Utah's Henry Mountains and Robbers Roost: Provo, Utah, Press Publishing, 224 p.

Marsh, Bruce, 2004, A magmatic mush column Rosetta Stone; the McMurdo dry valleys of Antarctica: Eos (Transactions, American Geophysical Union), v. 85, no. 47.

Nelson, S.T., Davidson, J.P., and Sullivan, K.R., 1992, New age determinations of central Colorado Plateau laccoliths, Utah: Recognizing disturbed K-Ar systematics and re-evaluating tectonomagmatic relationships: Geological Society of America Bulletin, v. 104, p. 1547-1560, doi: 10.1130/00167606(1992)104<1547:NADOCC >2.3.CO;2.

Nugent, A.T., Morgan, S.S., Boyd, B., Saint-Blanquat (de), M., and Horsman, E., 2003, Magnetic anomaly based interpretation of the magma feeders to the Trachyte Mesa laccolith, Henry Mts., Utah: Geological Society of America Abstracts with Programs, v. 35, no. 6, p. 339.

Peterson, F., Ryder, R.T., and Law, B.E., 1980, Stratigraphy, sedimentology and regional relationships of the Cretaceous System in the Henry Mountains region, Utah, in Picard, M.D., ed., Henry Mountains symposium: Utah Geological Association Publication 8, p. 151-170.

Pollard, D.D., and Johnson, A.M., 1973, Mechanics of growth of some laccolith intrusions in the Henry mountains, Utah, II; bending and failure of overburden layers and sill formation: Tectonophysics, v. 18, p. 311-354, doi: 10.1016/0040-1951(73)90051-6.

Pollard, D.D., Muller, O.H., and Dockstader, D.R., 1975, The form and growth of fingered sheet intrusions: Geological Society of America Bulletin, v. 86, p. 351-363, doi: 10.1130/0016-7606(1975)86<351:TFAGOF>2.0.CO;2.

Stokes, W.L., 1988, Geology of Utah: Salt Lake City, Utah Museum of Natural History and Utah Geological and Mineral Survey, 280 p. 
